\title{
A Theory of Financial Services Competition, Compliance and Regulation
}

\author{
Bryane Michael \\ Oxford University and University of Hong Kong \\ Joseph Falzon \\ University of Malta \\ Ajay Shamdasani \\ Thomson Reuters
}

\begin{abstract}
Do financial regulation advisors help their clients become more profitable? In this paper, we present a model where financial service firms may add to their own compliance teams or hire outside compliance advisors. We derive the conditions under which a financial services firm will want to hire a compliance services company, and show how much money they should spend. Financial services firms in competitive locations like Hong Kong and Singapore will particularly benefit (at least in the short run) from their services. We also show that their advice may lead to an embarrass de riches - whereby the lower compliance costs and higher profit advantages they confer may lead to more regulation. Regulators may furthermore tighten regulation - with the expectation that financial service firms will adapt somehow. We present a fresh perspective on the Menon Hypothesis, deriving conditions under which financial regulations help the competitiveness of an international financial centre. We provide five potential policy responses for dealing with ever ratcheting financial regulations.
\end{abstract}

JEL Codes: G18, G24, K40

Keywords: compliance industry, banking regulation, optimum regulation, compliance capacity

\section{Acknowledgements and disclaimers}

Funding for this study comes from the Hong Kong Theme-Based research council grant Enhancing Hong Kong's Future as a Leading International Financial Centre. The ideas and opinions in this paper remain ours and not those of any institution to which we are affiliated. 


\section{Contents}

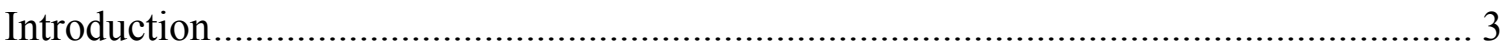

Overview of the Stylized Facts and Relevant Literature .......................................... 4

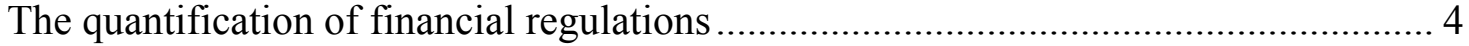

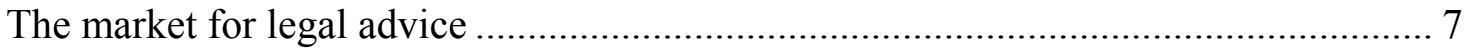

Model Set-Up: How Regulation affects Compliance Spending .................................... 8

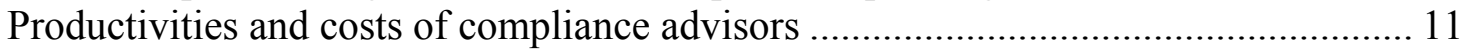

Allowing for profits and complementarities between advisors ................................ 13

Effect of complementarity on compliance advice and an equivalence hypothesis....... 17

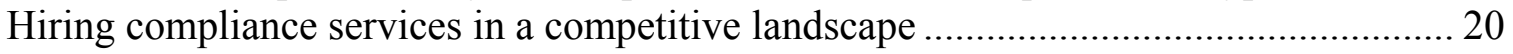

Compliance advisors' productivity in comparative perspective .............................. 20

Financial firm competition and compliance productivity growth............................... 22

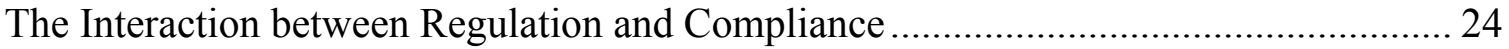

The Effect of Regulation on Compliance Advisory ................................................... 25

Short-term and longer-term relationship between regulation and compliance ............ 27

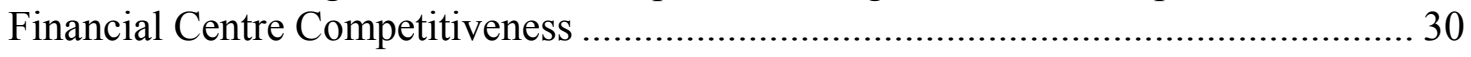

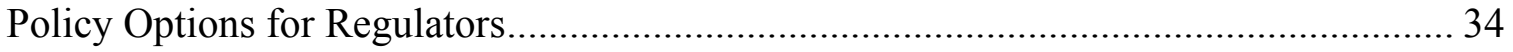




\section{A Theory of Financial Services Competition, Compliance and Regulation Bryane Michael, Joseph Falzon and Ajay Shamdasani}

\section{Introduction}

Since 2008, financial regulators have imposed large swaths of new regulations on financial institutions. To adapt to these new regulations - from Dodd-Frank to EMIR financial institutions have sought advice from a new class of infomediary. These information intermediaries specialise in providing regular regulatory monitoring, briefings, advice on, and even in-house computerised knowledge management and collaboration tools which allows these financial firms' lawyers, compliance staff, auditors and even external advisors to collaborate and exchange regulatory information. Thompson Reuters and CAPCO represent two well-known names in this space. Yet, the industry for providing information, advice and value-added services around financial regulation grows. How do compliance advisors help financial institutions adapt to financial regulation? How does such adaption affect regulators' decision to regulate in the first place?

In this paper, we model the way financial regulation advisors help improve financial institutions' profitability. We show that expanding a financial institution's compliance capacity may result in benefits to the individual financial services firm. We also show that in the presence of competition between financial services firms, competitive pressures lead to expanding compliance productivity - and thus compliance capacity. Regulators who observe such increasing compliance productivity impose more regulations. Eventually, the growth of new financial regulations and compliance productivity may equalize over time. Yet, in the short-run, over-zealous regulators (expecting future compliance productivity) may impose profit-damaging regulations harming the competitiveness of the financial industry they regulate.

We organise our paper as follows. The first section reviews some of the relevant literature - highlighting the lack of models for thinking through the interplay between compliance sector development and financial regulation. We also present in some detail a measure of the "level" of financial regulations - a key variable for any thinking about regulations in our model and testing it someday. The second section presents the set-up for our model - a basic profit maximisation problem with a labour/regulation constraint and a profit/labour constraint. Basically a two-sector model, we divide financial regulation advisors into in-house lawyers and outsourced compliance service providers. The third section presents our dynamics of competition in our model - showing how financial firm competition leads to higher productivity in the compliance sector. The fourth section provides the meat of the paper - showing the way regulation and financial service providers' productivity interact over time... both indirectly responding to changes in financial firms' profits. The fifth section presents strategies for testing some of our key propositions empirically. The brief sixth section provides 4 policy options. The final section concludes. 


\section{Overview of the Stylized Facts and Relevant Literature}

A relatively well-developed industry exists to inform financial services firms about changing financial laws. Services like Thompson Reuters' Accelus, the Policy and Regulatory Report (PaRR), CAPCO, Bloomberg and Wolters Kluwer represent some of the better-known stand-alone service providers. ${ }^{1}$ Most the top-tier global law, consulting and audit firms also provide their financial institutional clients with regular updates on legislative and regulatory changes affecting their business. Some of the names appearing on the first page of a Google search include Baker \& McKenzie, McKinsey, and KPMG. ${ }^{2}$ Yet, few economists have studied this segment of the larger market for professional services. What drives financial institutions to seek out third-party information about changes in financial laws in their jurisdictions? What drives the decision to monitor developments in-house rather than outsource such monitoring? What private benefits accrue to financial institutions which engage these financial service providers - and how does the rate of change in financial laws affect the value of their advice?

\section{The quantification of financial regulations}

Different jurisdictions have quantifiably different levels, changes and types of financial regulation. In recent years, scholars like Barth et al. (2013) have made strides in developing quantitative measurements related to various aspects of financial law across countries. Their measure assigns numerical values to various aspects of each country's banking law. For example, their proxy for a country which imposes a minimum capital entry requirement based on the bank's business registers a 1 if the country imposes such a requirement (or 0 otherwise). In such a way, they "break up" countries' banking laws into over 900 quantifiable aspects. With quantifiable proxies for a country's banking law, economists can develop indices which track the "level" countries' banking regulations, changes and the quantitative differences between specific aspects of banking law. ${ }^{3}$ These data have led to an explosion of econometric studies looking at the way banking regulation affects various aspects of the financial sector and other parts of the economy (Cihak et al., 2013; Vatnick, 2008).

Such quantification allows economists to model the stock, changes and quantitatively different aspects of financial law across countries. As shown in equation (1), the easiest way to describe the level of country $i$ 's regulations consists of assigning each of a country's $n$ financial law provisions with a number $m$ at time $t$. For example, $r_{3}=1$ if the third provision measures (a regulation requiring banks to file a suspicious transactions report equals 1 for amounts over $\$ 10,000,2$ for amounts over $\$ 50,000$ and so forth). Imagining that we can simply order countries alphabetically (or by any other procedure),

\footnotetext{
${ }^{1}$ A simple Google search on the terms "track financial regulatory changes Asia" provides a quick and impartial overview of the major service providers.

${ }^{2}$ We cite only the names appearing on the first page of a Google search to keep our citation of examples impersonal. Our mention of specific companies does not imply endorsement or criticism.

${ }^{3}$ We put "level" in quotes because most legal scholars, and even many economists, would balk at mapping a complex corpus of laws into a simple measure. We do not pass normative judgement on such a number. We only positively assert that economists can develop - and use in models - such a number.
} 
equation (2) shows the difference between country i's banking regulation and country $(i+1)$ on the list at time $t$. Equation (3) illustrates how one might get a feel for the difference in provisions across countries by looking at differences in specific provisions 3 and 4 between country 1 with countries 2 and 3. Clearly, with such data, the economist can compute curls, find orthogonal vectors and engage in a number of other techniques aimed at describing differences in regulatory provisions between countries.

$$
\begin{array}{ll}
R_{i t}=\sum_{j}^{n} r_{j t} & r_{j} \in[0, m] \\
\left(R_{(i+1) t}-R_{i t}\right)=\sum_{j}^{n} r_{(i+1) j t}-\sum_{j}^{n} r_{(i+1) j t} & \\
\left(\vec{r}_{(i+1) j}-\vec{r}_{i j}\right)=\left[\begin{array}{ll}
r_{2,3}-r_{1,3} & r_{3,3}-r_{1,3} \\
r_{2,4}-r_{1,4} & r_{3,4}-r_{1,4}
\end{array}\right] & \text { for } i=[1,2,3], j=[3,4]
\end{array}
$$

What do these differences look like? Figure $1 \mathrm{a}$ and $1 \mathrm{~b}$ shows the way a simple measure of banking regulation across countries has changed over time. Between 1999 and 2011, the Seychelles', Moldova's and Korea's financial regulation became increasingly "stricter" (as defined by Barth et. al.'s scale). Romania, El Salvador and Brazil significantly loosened their financial regulation during the same period. With a proxy for the "level" (and thus by computation the rate of change) of financial regulation, scholars can draw conclusions about how such levels affect regulatory costs, costs of compliance and other factors (Jackson, 2007). Such data even allow scholars like La Porta et al. (2006) to smugly describe "what works in securities laws."

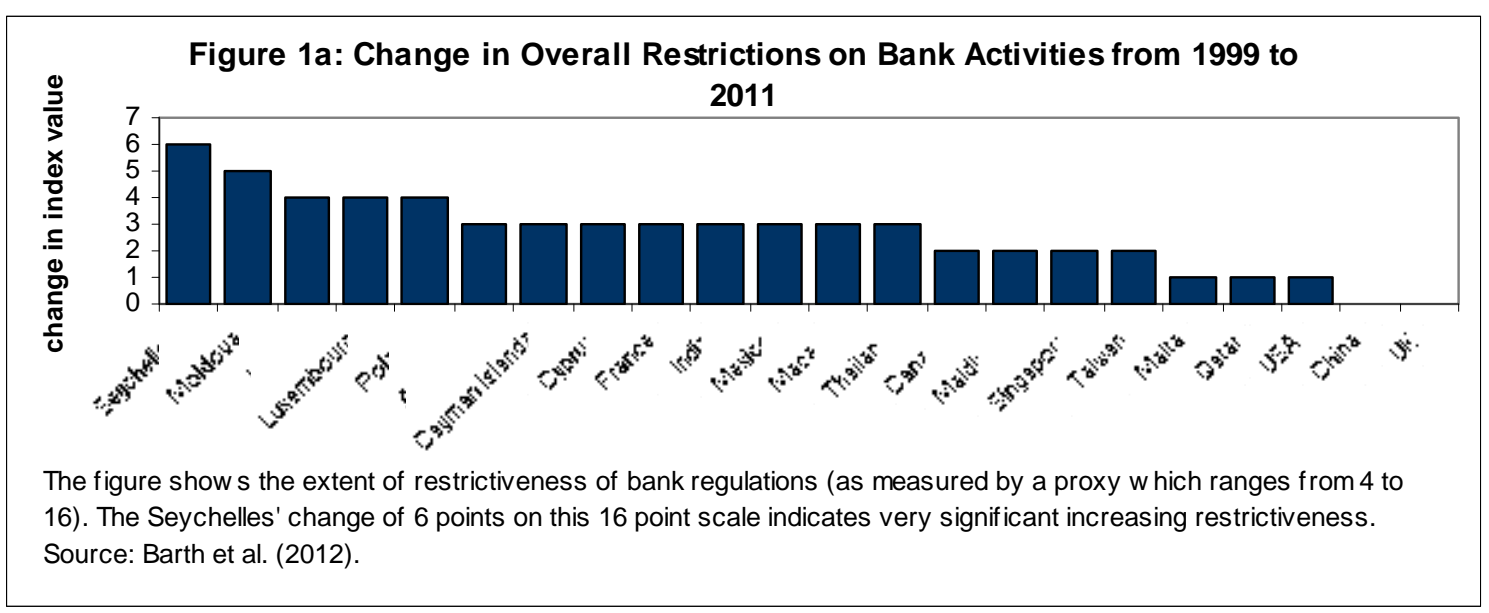




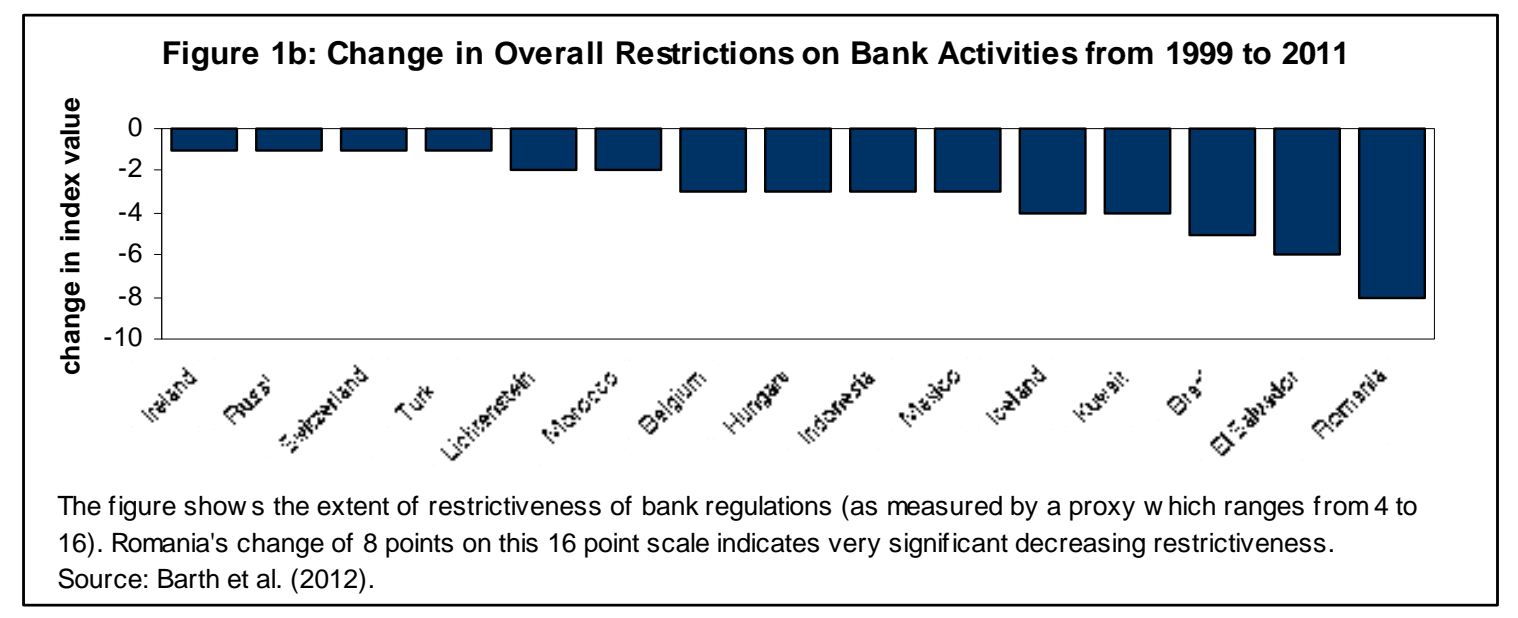

Such proxies also allow scholars like Cunningham and Zaring (2010) and others to explore the similarities and differences in countries' banking and securities regulation. What would such a grouping look like in practice? Figure 2 shows the extent of similarity between various jurisdictions' banking regulation. Using clustering analysis $-\mathrm{a}$ procedure which divides data into groups depending on similarities in the variance of banking provision scores - we see roughly four major groups. The first group, shown in dark blue, represents the major markets and banking centres. The second group, shown in slightly lighter blue, represents large, emerging markets like Mexico, and Russia as well as other OECD member countries like Canada and Australia. The third group represents alternative financial centres like Switzerland and Malaysia. The fourth cluster represents the few off-shore centres like Lichtenstein and Jersey. Despite whether we agree with the data or their interpretation - the fact remains that financial regulations can be quantified, scaled and compared. We show in the appendix how these data can be scaled onto the unit line.

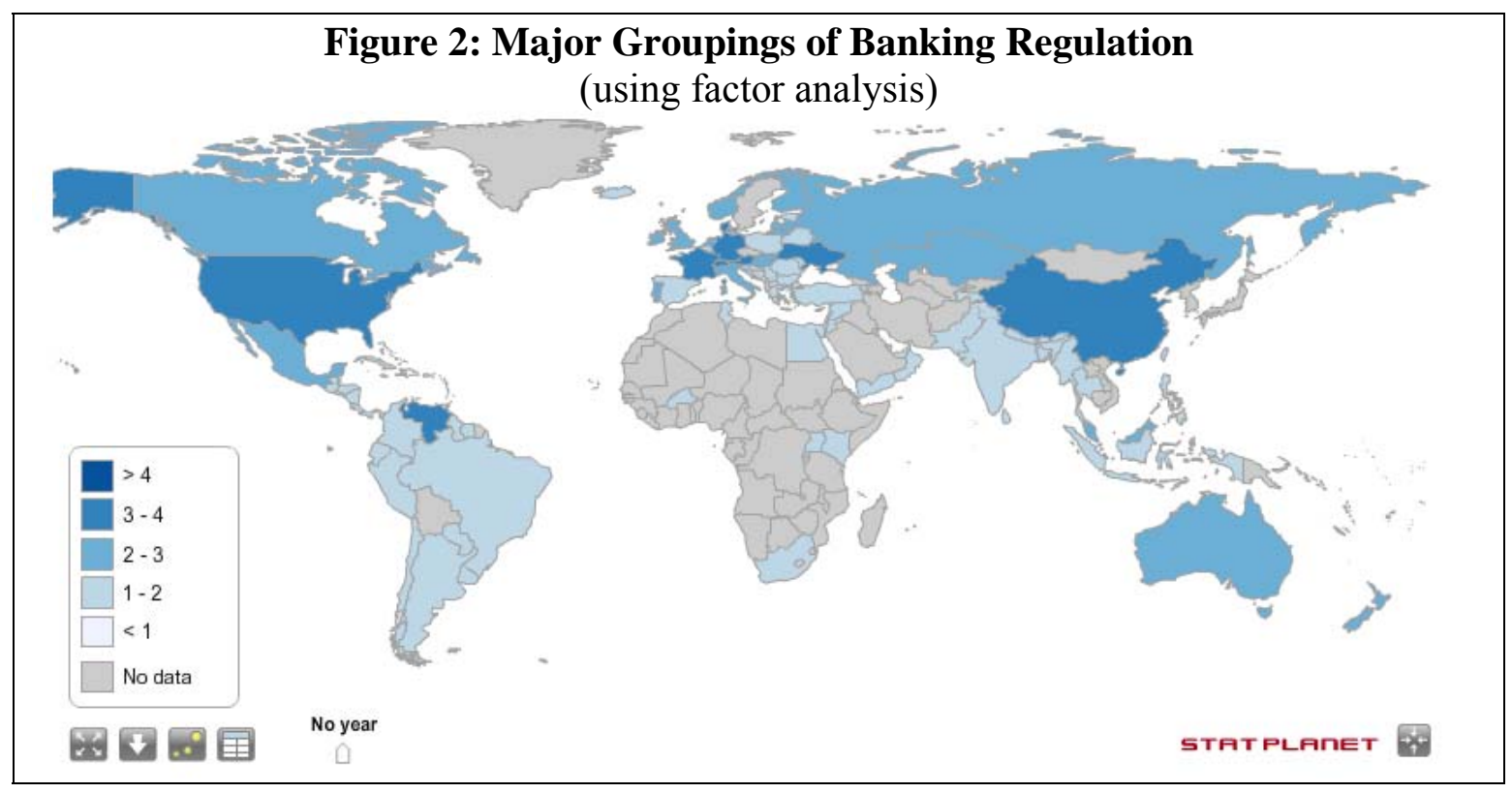


The figure shows the grouping of countries based on similarities and differences in their 2012 banking law. We used the World Bank's "scoring" of bank regulation along the over 900 dimensions they quantify. We then use factor analysis to identify groups of countries based on similarities in the variances of these scores. Source: authors, based on data provided by Cihak et al. (2013).

\section{The market for legal advice}

Academics have failed to look at closely the market for legal services in general - much less the sub-sector dealing with the supply of financial services compliance advisory services. Theorising about the size of the legal sector - and related market segments such as those offering specialist news and advice about financial law - has remained confined to very specific situations. ${ }^{4}$ For Galanter and Henderson (2008), they seek to explain the size and structure of the legal sector as the result of tournaments between lawyers. Publishing in the law journal setting, but deeply inspired by economic analysis, the authors show how the competitive interaction of lawyers helps determine the supply and cost of legal advice. Emons (2000) provides a similar type of analysis, looking at the level of legal services provided in a contingency-based pay contracting environment. He finds that lawyers have incentives to provide insufficient effort -- suggesting that a market distortion results in excess demand in a trial lawyer setting. Yet, by far, the traditional approach to modelling demand for legal advice consists of using the extent of commercial or personal conflict as the driver of demand for legal advisors' services (Iossa and Jullien, 2009). These approaches provide few insights when modelling the demand for lawyers providing advice about complying with financial laws.

Two flavours of models provide the closest analogue for our work. First, Garicano and Hubbard (2009) describe the how legal "niches" (like banking and securities law) develop as a function of overall market size and the size of a legal specialisation. They show that law firms do not group relatively unrelated practices (to diversify risk) and that lawyers tend to specialise. They show that transactions costs usually encourage lawyers to specialise - suggesting that any "financial services compliance sector" should grow over time due to a size effect. Second, Olsen (1999) looks at the way a stock of regulations affects the development of intermediaries who earn money by helping companies understand and comply with these regulations in a particular industry. In his study, he looks specifically at the stock of product health and safety regulations and the way such a stock of regulations affects compliance in the US Food and Drug Administration FDA-regulated industries. Olsen focuses more on the regulations themselves rather than the intermediary industry which arises to reduce the administrative burden (namely the transactions costs) of these regulations. Yet, no studies seem to bridge the gap in these two literatures.

The literature suffers from four lacunae for understanding how the financial sector compliance industry develops over time. First, "compliance" addresses a range of services, from simply broadcasting regulatory novelties to financial services firms (at one

\footnotetext{
${ }^{4}$ Part of such a lacuna comes from the lack of data. Authors like Tsolakis (2014) provide a financial snapshot of the legal services industry in the UK. However, these largely anecdotal accounts, which mix stories and pieces of data collected from a range of sources, do not provide scholars with sufficiently rigorous foundations for study.
} 
end of the spectrum) to providing specific assistance for complying with a specific provision like money-laundering-related know-your-customer rules (at the other end of the spectrum). Any model looking at the individuals and undertakings which provide legal information and advice to financial services firms must depict a "matching function" for translating regulation into financially profitable advice. In other words, a model must treat regulation as an input into financial services organisations' production function (like labour, capital, intermediate inputs and so forth). ${ }^{5}$ Scholars like Silver (2008) look at the effect regulation plays on the market for legal advice. Yet, few scholars have written about the market for legal advice about regulation.

Second, given the fungibility and diversity of legal advisors, any model would need to divide the market for advisors into insiders (in-house lawyers) and outsiders (external or outsourced compliance advisors). Such a model must thus describe the boundaries of the firm (both the compliance/law firm and the financial services firm). Authors like Krishnan (2007) have looked at the factors driving compliance and legal advisory outsourcing. Yet, the talk in the law reviews has not made its way into the economics journals.

Third, such a model must show how these compliance professionals evolve over time particularly in response to evolving regulation, much less considering the endogenous determination of regulation and compliance effort/productivity. Helleinera and Pagliaria (2011), in their review of research about international financial law, lament the lack of theorisation about fragmentation of, compliance with, and development of, such financial law. Put simply, we have few models about how national regulators make financial law. We have even fewer models of the compliance processes used by banks, financial institutions and other economic actors. The literature tends to view "compliance" as a binary variable - comply or don't. Scholars have yet to model the cost of compliance. Scholars like Akhigbe and Martin (2006) and Jain and Rezaee (2010) look at the impacts of the compliance decision. Yet, viewing compliance as an economic input, with costs, productivity, opportunity costs vis-a-vis capital and labour remains alien to lawyers and economists alike.

\section{Model Set-Up: How Regulation affects Compliance Spending}

We start by modelling how financial regulation affects a financial service firm's profits. The financial service firm's production consists of generating some quantity of service (which we label as $\mathrm{Q}$ ) and earns a rate of return for the loans, services or any other $Q$ you wish to imagine. That return i represents a proportion of the value of the services the firm offers. As shown in equation (4), the cost of compliance comes from transforming a stock of regulations $R$ in a convex investment function $I(R)$ and "mixing" them with service provision. Reflecting real-life financial services, the firm "attaches" regulatory

\footnotetext{
${ }^{5}$ Most economists, to the extent they model regulations, treat regulation as a constraint or barrier to production. In fact, regulation contained enshrined instructions for accomplishing many regulated tasks. As such, the codified disembodied knowledge enshrined in a country's massive corpus of financial law represents a valid factor of production, as important as a computer code or marketing knowledge.
} 
monitoring, compliance advice, and other activities (which naturally depend on the level of regulations $R$ ) to the services it creates.

$\pi=i Q-I(R) Q$

Our treatment of the way firms transform regulations into profits represents one of the most novel aspects of our model. The parameter $a$ represents the productivity by which financial firms transform regulations into costs (and thus profits). ${ }^{6}$ The term $(1-\alpha)$ reflects the marginal cost/productivity of in-house lawyers transforming regulations into costs. Financial firms use a mix of in-house lawyers $L$ and outside compliance advisors $C$ to generate transform regulations into costs. As per authors like Dehnad and Dehnad (2013), the term $\tau$ represents the interaction between this advice - where spending may consist of technology which helps different departments of a financial services firm pull together information from a compliance expert (for example). We deliberately and blatantly leave capital out of the model to focus on the way financial use lawyers, rather than capital. ${ }^{7}$ Revenues growing linearly, costs potentially growing exponentially, and financial firms also need to dish out money for two different types of lawyers.

$$
\begin{aligned}
& \pi=i Q-\frac{1}{1-\alpha} a^{(1-\alpha) R} Q-(\tau \cdot L \cdot C) \\
& \quad \text { where } 0>\alpha>1, \mathrm{R} \geq 0, \mathrm{Q} \geq 0, \text { and }(i, a, L, C, \tau) \geq 0 .
\end{aligned}
$$

These financial service firms operate under two constraints. First, as shown in equation (6), firms will always hire a number or labour-equivalent units of in-house lawyers $L$ and engage consultants $C$ to deal with the existing stock of regulations $R$. We can think of the lawyers' productivity $(\gamma)$ and consultants' productivity $\theta$ as geometrically converting manpower into pages of compliance. The terms $a$ and $b$ linearly convert this labour into regulation-related compliance. Thus the way to read equation (6) would be that the number of pages of regulations (on the left-hand side) exceeds or equals the number of effective pages of compliance (on the right-hand side). Equation (7) requires financial service firms' profits to exceed the amount paid for lawyers $w$ and compliance consultants $c$, as well as some minimum required profit level $\pi_{\min }$. Such a minimum profit level represents opportunity cost or a minimum defined profit level for the industry - and firms earning less go out of business or into other business lines.

$$
\bar{R} \geq \frac{a}{\gamma} L^{\gamma}+\frac{b}{\vartheta} C^{\vartheta}
$$

\footnotetext{
${ }^{6}$ We show shortly that a serves a dual purpose in our model - as in-house lawyers' productivity. Thus, as they become more productive, they become more costly and reduce profits. We discuss this view of lawyers as a cost-centre later.

${ }^{7}$ Readers looking to extend or criticize the model could view $Q$ as a function of capital $K$. The chosen functional form would have different implications for the way the firm deploys capital. Similarly, the firm works in the crevices where unprofitable regulation does not chock-off the firms profitable activity. We do not constrain $\mathrm{Q}$ as revenue grows linearly but costs increase geometrically, guaranteeing a maximum level of profitable production at some quantity $\mathrm{Q}$.
} 
Financial service firms maximise their profits, subject to the constraints that compliance spending imposes on them. Equation (8) shows the maximisation problem, where financial firms adjust their quantity produced, number of lawyers, consultants and the opportunity cost of extra regulations and profits. Why does the same parameter $a$ enter two times? Lawyer's ability to turn man-hours into pages of regulatory compliance equals the same factor which turns regulation into costs. As lawyers become more productive on the constraint side, they become more costly on the production function side. This novel formulation reflects the standard view that blossoming legal and compliance departments inside of financial firms represent a large (but necessary) drag on the organisation in a way that outside compliance workers do not. Given the nonlinearities involved, can not yet solve $\mathrm{L}$ and $\mathrm{C}$ completely. However, we can solve for the linear bits (as shown in equations (10) and (11) and provide the implicit solution for the non-linear part as shown in equation (9).

$$
\begin{aligned}
& \max _{Q, L, C, \lambda, \lambda} \pi=i Q-\frac{1}{1-\alpha} a^{(1-\alpha) R} Q-(\tau \cdot L \cdot C)-\lambda_{R}\left(R-\frac{a}{\gamma} L^{\gamma}+\frac{b}{\vartheta} C^{\vartheta}\right) \\
& -\lambda_{\pi}\left(\pi-\bar{\pi}_{\min }+w L+c C\right) \\
& \frac{\tau\left(\pi-\bar{\pi}_{\min }\right)-w \lambda_{\pi}(c-1)}{\lambda_{R}}=b C^{\vartheta-1}+c a L^{\gamma-1} \\
& L^{*}=\frac{\lambda_{\pi} c+\lambda_{R} b C^{\vartheta-1}}{\tau} \\
& C^{*}=\frac{\lambda_{R} a L^{\gamma-1}+\lambda_{\pi} w}{\tau}
\end{aligned}
$$

What does the solution to this non-linear system of equations look like? Figure 3 illustrates two cases showing how changes in external factors can either increase or decrease the amount of compliance advisory services that financial services firms may require. ${ }^{8}$ On the left-hand side of the figure, we show a base case - setting most of the parameter values to one. On that graph, we show the balance between in-house counsel advisory services and external compliance advisory for a fixed level of regulation. At the optimum level of in-house staffing, the trade-off between in-house lawyers and the amount of external compliance services increases steeply. A large number of in-house lawyers are needed to compensate for a relatively small increase in external advisory. At the optimum level of external compliance advisory, more consulting provides a poor substitute for in-house expertise. The equilibrium balance between internal and external staff - for this base case parameterization - consists of roughly 2 consultants for every one in-house lawyer. If the base case holds as a description of the relationship between in-house counsel and external compliance consultants, before taking the effect of profits

\footnotetext{
${ }^{8}$ The figure shows solutions for equations (10) and (11) only. We want to provide an intuition for the way several of the first order conditions work together before using the others.
} 
and complementarities into account, financial services firms should encourage far more external advice than they retain in in-house legal advisory.

Figure 3: Changes to In-House Counsel and External Compliance Advisors
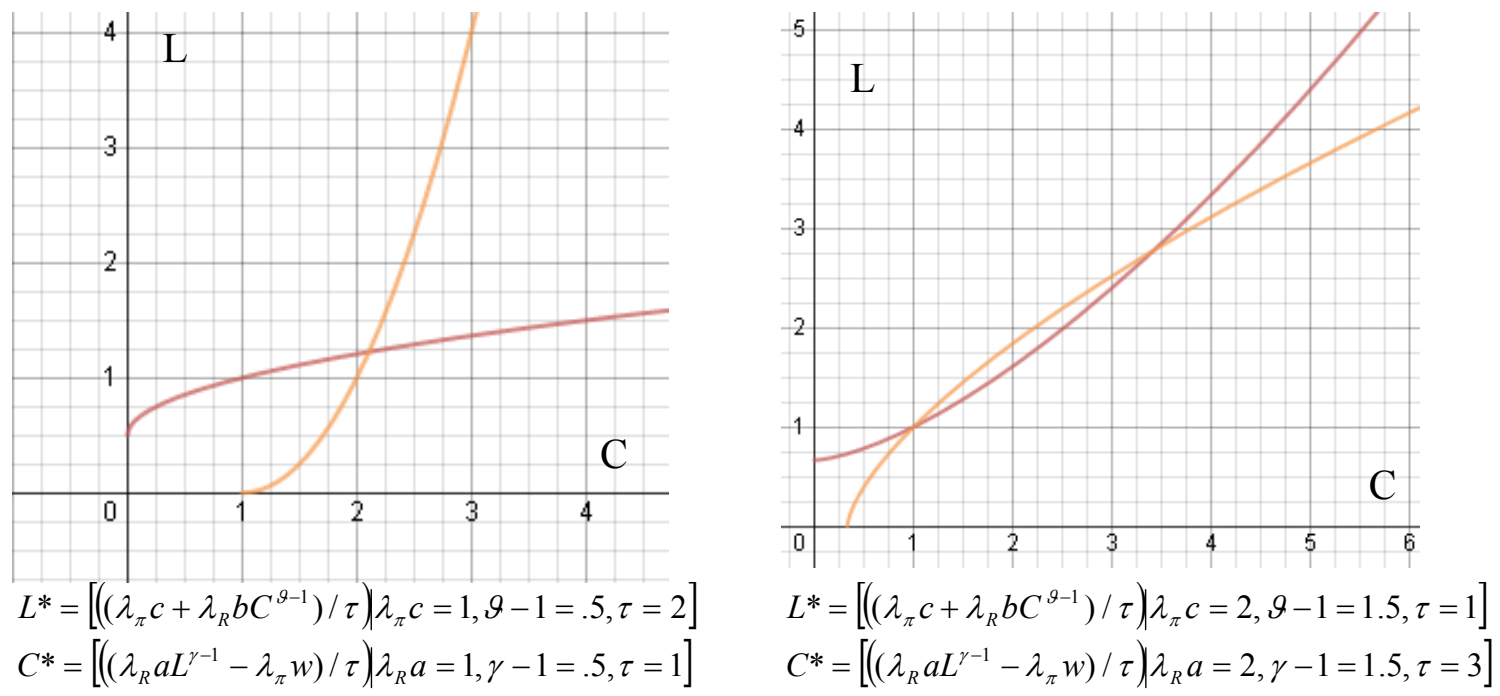

Even minor changes to the base model shows how the proportion of in-house lawyers to outside compliance consulting changes. On the right hand panel, we show an increase in the cost of consultants, an increase in the productivity of consultants and an increase in the synergies between lawyers and consultants. Even minor changes to the model illustrate the existence of multiple equilibria. The equilibrium level of lawyers and consultants either settles at 1 or roughly 3 . As such multi-equilibria show, and to foreshadow a later result, similar levels of regulation and profits can correspond with very different levels of compliance expenditure.

Productivities and costs of compliance advisors

Lemma 1: The use of outsourced compliance relative to in-house counsel depends on a productivity effect $\lambda_{R}\left(a L^{\gamma-1} / b C^{\vartheta-1}\right)$ and a cost effect $\left(\lambda_{\pi} w / \lambda_{\pi} c\right)$.

As shown in Figure 3, the optimal amount of in-house counsel hired (as a function of external compliance advisors) can settle in equilibrium at one of several points depending on the model's parameterization. Expressing such external compliance as a proportion of labour gives an expression similar to equation (12). Such a proposition increases as the productivity of in-house counsel increases and as their wages increase.

$\frac{C^{*}}{L^{*}}=\frac{\lambda_{R} a L^{\gamma-1}+\lambda_{\pi} w}{\lambda_{R} b C^{\vartheta-1}+\lambda_{\pi} c}$ 
The $\lambda_{R}\left(a L^{\gamma-1} / b C^{\vartheta-1}\right)$ term clearly represents a type of productivity effect, as the optimal amount of each factor of production decreases with increases in productivity of the other (complementary or substitutable) factor of production. The $\lambda_{R}$ term represents the "shadow price of regulation." In other words, how does an increase in the regulation level affect the amount of profits which financial service firms must spend for compliance activities? The cost term $\left(\lambda_{\pi} w / \lambda_{\pi} c\right)$ compares the relative cost of using inhouse lawyers compared with outside compliance advisors. Unsurprisingly, as lawyers' wages increase, the optimal amount of outside compliance staff rises.

Lemma 2: The optimal rule-of-thumb hiring of external compliance advisors consists of:

$$
C^{*}= \begin{cases}\sqrt[a-2]{\frac{a(\gamma-1)}{b(\vartheta-1)}} L^{\frac{\gamma-2}{g-2}} & \text { in the case where compliance-to-lawyer ratios vary } \\ \sqrt[9-1]{\frac{-\lambda_{\pi}}{\lambda_{R} b}(c+w)}+\sqrt[9-1]{\frac{a}{b}} L^{\frac{\gamma-1}{g-1}} & \text { in case where compliance-to-lawyer ratios equal } 1 \text { and } \\ \frac{-\lambda_{\pi}}{\lambda_{R} b}(c+w)+\frac{a}{b} L & \text { with constant returns to all regulatory compliance advisors }\end{cases}
$$

How much compliance services - abstracting from profits and complementarities should financial service firms engage? We know that, at the equilibrium level, the change in compliance consulting spending with respect to changes in lawyer staffing changes by the same amount as the change in lawyer staffing to changes in compliance spending - or $\partial \mathrm{C} / \partial \mathrm{L}=\partial \mathrm{L} / \partial \mathrm{C}{ }^{9}{ }^{9}$ The first equation in lemma 2 shows that optimal, equilibrium level. The second part of the lemma sets $\mathrm{C}^{*} / \mathrm{L}^{*}$ equal to 1 and then rearranges terms for $\mathrm{C}^{*}$. The third part of the lemma sets $(\theta-1)$ and $(\lambda-1)$ equal to 1 and solves for $C^{*}$. As found in other studies like Simmons and Dinnage (2011), factors like profits or quantity produced do not determine the optimum amount of lawyer-hiring and outsourcing. Given that we have abstracted from these issues for the time being, such a result is not surprising.

Corollary 1: Holding everything else constant, and in the absence of profit and complementarities between factors of compliance, $C / L>1$ (and changes in $\partial C / \partial L>1$ ) reflect higher productivity of consultants relative to in-house lawyers.

How can we think about the way financial firms hire compliance consultants versus inhouse lawyers at the margin? As a thought experiment, we can increment $L$ and $C$ slightly and record that procedure with the $\Delta$ operator. Equation (13) shows the effect of incrementing the $\mathrm{C} / \mathrm{L}$ ratio shows in equation (12) in this way. The numerator represents the effect of changing L slightly and the denominator represents the change in L of incrementing $\mathrm{C}$ slightly. Unsurprisingly, particularly where w and c either remain fixed in the short-term or reflect marginal productivities anyway, then the labour type mix reflects the regulation-tackling ability of each group of legal advisors.

\footnotetext{
${ }^{9}$ In other words, the convex and concave curves in figure 3 should intersect at one point, where the marginal rate of substitution between in-house lawyers and outsourced compliance consultants equalizes.
} 
$\Delta \frac{C^{*}}{L^{*}}=\frac{a(\gamma-1)}{b(\vartheta-1)}$

The literature - exclusively from the law reviews - takes contradictory views on the productivity of in-house counsel relative to external advisors. Langevoort (2012) has argued that management tends to "capture" in-house lawyers, suggesting that $b<a$ and $\theta<\gamma$. Moreover, external legal service providers can specialise on a narrow service without the tugs of daily organisational minutae. At the other end of the debate, authors like Schwarcz (2008) argue that in-house lawyers tend to outperform their external peers due to more in-depth knowledge of the company and industry they work for. In a Schwarczian world, $\theta>\gamma$ due to the usual gains from specialisation. Both perspectives reflect the usual conflict in organisation theory about where the boundaries of the firm best lead to the specialisation which generates profits for the firm. If we observe financial services firms expanding their purchase of outside compliance services relative to expanding the work of in-house lawyers, we can deduce that such decisions reflect the gains from specialisation outside relative to insider the financial services firm. $^{10}$

\section{Allowing for profits and complementarities between advisors}

What happens when we take profits and complementarities into account? Equation (21) shows the full expression for $\mathrm{C}$ and $\mathrm{L}-$ an expression basically unsolvable analytically. The solution to this part of the system yields equations (16) and (17). ${ }^{11}$ Unsurprisingly, the solution to this non-linear model basically says that compliance spending and spending on lawyers represent a function of the model's parameters. More surprisingly, the solution for $\mathrm{L}^{*}$ looks almost exactly like the solution for $\mathrm{C}^{*}$ - except for the omission of $\exp ((1 /(\theta-1) * \ln (\cdot / \lambda b))$. These terms basic scale down in-house lawyers as the productivity of compliance consulting rises.

$$
\begin{aligned}
& \tau\left(\pi-\bar{\pi}_{\text {min }}\right)-w \lambda_{\pi}(c-1)=\lambda_{R} b\left[\frac{\lambda_{R} a L^{\gamma-1}+\lambda_{\pi} w}{\tau}\right]^{\vartheta-1}+\lambda_{R} c a\left[\frac{\lambda_{\pi} c+\lambda_{R} b C^{\vartheta-1}}{\tau}\right]^{\gamma-1} \\
& C^{*}=\exp \left[\frac{1}{\theta-1} \ln \left(-\frac{\mu \exp -(\gamma-1) e^{Z} a \theta+R \gamma \theta+\gamma b \exp \left(\left(\ln \left(\frac{-\delta}{\lambda b}\right) \theta\right) / \theta-1\right.}{\lambda b}\right]\right. \\
& L^{*}=\exp \left[-e^{Z} a \theta+R \gamma \theta+\gamma b \exp \left(\left(\ln \left(\frac{-\delta}{\lambda b}\right) \theta\right) / \theta-1\right]\right.
\end{aligned}
$$

for $\mu=-\tau \pi+w \lambda_{\pi} c-w \lambda_{\pi}+\lambda_{R} c a \quad$ and $\quad \delta=\mu e^{\frac{Z(\gamma-1)}{\gamma}}-\tau \pi+w \lambda_{\pi} c-w \lambda_{\pi}+\lambda_{R} c a$

\footnotetext{
${ }^{10}$ A third case exists, where the two represent perfectly substitutable inputs. We discuss this in a later section.

${ }^{11}$ Because of this complexity, we divided the first order conditions to the optimization problem shown equation (8) into parts and described the nature of that solution.
} 
We can look how the expression behaves under certain circumstances in order to understand how compliance-related advisory relates to profits and complementarities between in-house counsel and outside compliance advisors. Setting $\theta$ and $\lambda$ equal to 1 gives us the much simpler case shown in equation (18) and equation (19). Solving for the optimum $\mathrm{C}$ and L under these specific assumptions leads to equations (20) and (21). Equation (22) shows the external compliance to in-house lawyer ratio which we can analyse more easily.

$$
\begin{aligned}
& \frac{\tau\left(\pi-\bar{\pi}_{\text {min }}\right)-w \lambda_{\pi}(c-1)}{\lambda_{R}}=c a L+b C \\
& R=a L+b C \\
& L^{*}=\frac{a(c-b)}{\lambda_{R}}\left(\tau\left(\pi-\bar{\pi}_{\text {min }}\right)-w \lambda_{\pi}(c-1)-\lambda_{R} R\right) \\
& C^{*}=\frac{b(c-1)}{\lambda_{R}}\left[\lambda_{R} c R-\tau\left(\pi-\bar{\pi}_{\text {min }}\right)-w \lambda_{\pi}(c-1)\right] \\
& \frac{C^{*}}{L^{*}}=\frac{b(c-1)\left[\lambda_{R} c R-\tau\left(\pi-\bar{\pi}_{\min }\right)-w \lambda_{\pi}(c-1)\right]}{a(c-b)\left(\tau\left(\pi-\bar{\pi}_{\min }\right)-w \lambda_{\pi}(c-1)-\lambda_{R} R\right)}
\end{aligned}
$$

The intuition from equation (12) continues to hold. Increasing payments to compliance consultants tends to increase their numbers (as shown by comparing the parenthetical parts of equation (22). Such an effect likely results from an income effect, as resources fall for hiring legal advisors and making the less costly (on an overall basis) outsourced compliance staff more desirable.

Lemma 3: Under the case of constant productivity, when financial firms increase their profits (and assuming they haven't completely dealt with regulatory obligations), they increase their employment of $C$ relative to $L$ if $b\left(w c^{2}-c+w+1\right)>a w\left(c^{2}-b c\right)$ with a "wage" of $\frac{-b}{2}+\frac{\sqrt{b^{2}-2 b-4 b w+4(a-b) w^{2}+4(a-b) w+1}}{w(a-b)}$

Unsurprisingly, employment of outside compliance professions increases to the extent they can "make more pages of compliance" (to continue with our analogy for compliance production in our model). To the extent $b>a$, financial firms want more C. At first glance, such a result may seem counter-intuitive. Given a fixed amount of regulation, firms may want to avoid compliance staff that act like a teacher's pet, complying really, really well with obligations. Yet, in this case compliance refers to the amount of compliance achieved for each dollar spent on compliance activities. As described in Figure 4, financial firms in the post-2008 rush to hire compliance staff focused on hiring high productivity staff. ${ }^{12}$

\footnotetext{
${ }^{12}$ For a description of this rush, see Deloitte. (2014). Demand for Compliance and Risk Skills Leaves a Talent Shortage. Wall Street Journal, 13 August. Available online at: http://deloitte.wsj.com/riskandcompliance/2014/08/13/demand-for-compliance-and-risk-skills-leaves-atalent-shortage/
} 


\section{Figure 4: The Case for Experienced Compliance Advisors}

What does "high productivity" mean in the context of financial services compliance? The post-2008 boom in compliance staff hiring - and the extensive internet chatter about desirable candidate individuals and companies for compliance roles - provides a glimpse at how these financial service firms define quality and productivity (basically the $\lambda$ and $\theta$ in our model and to a lesser extent $a$ and $b$ ). Experience lies at the heart of every discussion about the war for talented compliance staff. "Now that risk is really briefing the board at every meeting, the risk officer has to be a much more senior level hire with more gravitas, with more influence and communication skills,' said Lisa Zonino, a principal at recruiter Egon Zehnder in New York." ${ }^{13}$ Recruiters and banks stress experience more than knowledge. Experience, rather than skills or knowledge, allows banks to comply quickly and cheaply. Thinking about compliance productivity as the ability to match a set $R$, we understand more clearly why employers put a premium on experience. Yet, as regulators move towards results-based and/or principles-based regulation, such a situation might change. Maybe we will one day talk about "better compliance."

The change in employment from changes in consulting fees comes from the ratio of consulting to lawyers. Let's look again at equation (22) and only those parts dealing with changes in profits. Equation (23) shows the $\mathrm{C} / \mathrm{L}$ again, using the $\Delta$ operator this time to denote changes in variables dealing with profits. As profits nudge up or down, the $\mathrm{C} / \mathrm{L}$ ratio changes as shown. Under what conditions do financial firms hire more compliance consultants, relative to in-house lawyers? Equation (24) shows the effect of setting $\Delta(\mathrm{C} / \mathrm{L})>1$, and rearranging some terms. Equation (25) solves the solution for the quadratic function $c$. The equation basically says that the proportion of outsourced compliance services relative to in-house lawyer services increases at the margin when their productivity or lawyers' wages increase. Under these very specific assumptions, as shown in Equation (25), the per-unit "wage" for compliance consultants simply gathers the terms of the quadratic equation and solves for $c$.

$$
\begin{aligned}
& \Delta \frac{C^{*}}{L^{*}}=\frac{-b(c-1)(1+w(c-1))}{a(c-b)(1-w(c-1))} \\
& b\left(w c^{2}-c+w+1\right)>a w\left(c^{2}-b c\right) \\
& c= \pm \frac{1}{2} \frac{-b+\sqrt{b^{2}-2 b-4 b w+4(a-b) w^{2}+4(a-b) w+1}}{w(a-b)}
\end{aligned}
$$

\footnotetext{
${ }^{13}$ Armstrong, Rachel. (2012). Compliance Jobs See Major Salary Hikes As Tough Bank Regulations Boost Demand. Reuters, 25 November. Available online: http://www.huffingtonpost.com/2012/11/25/compliancejobs-salary-hikes_n_2189005.html
} 
We have noted previously that outsourced compliance consultants can increase demand for their services by raising their fees. Now that we have included profits and complementarities into our analysis, under what conditions does $d C / d c>0$ ?

Lemma 4: Compliance service providers should get more business by lowering their fees when $c<((\tau / 2 w)+1)$, or when these fees are less than the complementarities compliance hiring provides and when lawyers wages rise.

At first glance, compliance consultants - in theory - look like they can raise demand by raising their fees when their fees are a bit higher than lawyers' wages. Equation (26) rewritten and rearranges the similar terms from equation (21). As equation (27) shows, $\mathrm{dC} / \mathrm{dc}>0$ when these consulting fees are less than 1 plus a tiny bit more. Recall that we set many of the variables to 1 to obtain a tractable example. Thus, in this world where unity represents normal, these compliance consultants can get away with charging a bit more than in-house lawyers. ${ }^{14}$ Once we allow for profits, the more difficult to understand equation (28) governs the ability of compliance consultants to raise demand for their services by rising rates. Increased regulation makes raising rates easier, as does increasing complementarities between $\mathrm{C}$ and $\mathrm{L}$ and rising profits. ${ }^{15}$

$$
\begin{array}{ll}
\frac{\partial C^{*}}{\partial c}=\frac{1}{\lambda_{R}}\left[2 \lambda_{R} R b c-\lambda_{R} R b-\tau b\left(\pi-\bar{\pi}_{\min }\right)-2 b w \lambda_{\pi} c-2 b w \lambda_{\pi}\right] \\
\frac{\partial C^{*}}{\partial c}>0 \text { when } \quad c<\left(\frac{\tau}{2 w}+1\right) \\
\frac{\partial C^{*}}{\partial c}>0 \quad \text { when } & c^{\prime}<\frac{R \lambda_{R}+\tau\left(\pi-\bar{\pi}_{\min }\right)+2 w \lambda_{\pi}}{2\left[R \lambda_{R}-w \lambda_{\pi}\right]}
\end{array}
$$

Corollary 2: increases in consulting fees decrease demand for compliance consultants for small fee levels ${ }_{c<\frac{R \lambda_{R}+\tau\left(\pi-\bar{\pi}_{\min }\right)+2 w \lambda_{\pi}}{2\left(R \lambda_{R}-w \lambda_{\pi}\right)}}$ and/or when the level of regulation exceeds a certain limit $R>\frac{\tau\left(\pi-\bar{\pi}_{\min }\right)-2 w \lambda_{\pi}(c-1)}{\lambda_{R}(2 c-1)}$.

We already showed above how we derived the condition whereby $\mathrm{dC} / \mathrm{dc}>0$ when $\mathrm{c}=\mathrm{f}\left(\mathrm{R} \lambda_{\mathrm{R}}, 1_{\pi}, \pi, \tau\right)$. By backing up to (26) or by rearranging equation (28), we can solve for $\mathrm{R}$. Such a solution implies that compliance consultants' employment and fees increase when the financially equivalent value of regulation significantly exceeds financial firms' profits, when lawyers' wages fall, and when the effect of regulations on firms' profits rises (becomes more harmful).

\footnotetext{
${ }^{14}$ To take a simple numerical example, imagine that $\tau=0.6$ and $w=1$. In this setting, $c<1.3$ in order that $\mathrm{dC} / \mathrm{dc}>0$. Naturally, as the hiring of more $\mathrm{C}$ increases, $\mathrm{c}$ will rise and financial will lose their zeal for hiring/replacing lawyers with outside compliance advisors.

${ }^{15}$ The term $R \lambda_{R}$ represents the negative impact on profits of increasing regulation. Similar negative terms in the numerator and denominator become positive (a negative divided by a negative is a positive). Rising wages in the numerator swamp out those in the denominator, making increases in wages good for compliance consultants.
} 


\section{Effect of complementarity on compliance advice and an equivalence hypothesis}

Maybe it doesn't matter whether the financial services firm uses in-house lawyers or outside compliance advisory. Rosen (2008) has argued that consulting-style contracts have permeated corporations and "companies use lawyers just like they use any consultant" (1). Henderson (2011) has decried present-day lawyers as "project managers." Rostain (2008) notes that the two groups, rather than simply replaceable cogs in international business, form a symbiotic relationship. Elimination of one group may hurt financial firm productivity. But (at the risk of over-interpreting the gaps in their argument) simply moving individual members from one group to the other should not affect financial firms' productivity.

If in-house counsel really does operate like an outside consultant, then the choice of $L$ or $C$ would not matter. Indeed, economic theory predicts that, at the margin and in the longrun, factor payments and productivities balance out. Under what conditions does our model predict that in-house lawyers and outside compliance counsel are equivalent (and thus the choice between then irrelevant)?

Lawyer-consultant equivalence holds only when all their payments and productivities are equal. Recalling from equation (12) that the hire of compliance relative to in-house counsel equals depends basically on each one's productivity and cost. The condition rewritten in equation (28) holds true when $w=c, b=a$ and when $\theta=\gamma$. Interestingly, when the shadow price of regulation on profits equals zero, this also leads to indifference between in-house council and outside compliance advisors.

$$
\lambda_{R} b C^{\vartheta-1}+\lambda_{\pi} c=\lambda_{R} a L^{\gamma-1}+\lambda_{\pi} w
$$

Even in the limited confines of our model, we know that lawyer-consultant equivalence does not hold. Equations (29) show the change in employment in each sub-sector, for a change in the complementarity between them. For a small change in the way they work together to engage in compliance activities, lawyers' sensitivity to changes in such a complementarity is higher. When $\partial \mathrm{C} / \mathrm{d} \tau=\partial \mathrm{L} / \mathrm{d} \tau$, the effect of a slight change in the complementarity between in-house lawyers and compliance consultants equally affects their employment. As equation (30) notes, compliance consultants' employment change more with $\tau$ than lawyers when their productivity is higher. Such a condition only holds when compliance costs are relatively low (reflecting their low productivity). Figure (31) shows the expression slightly differently (as a series expansion).

$$
\begin{aligned}
& \frac{\partial L^{*}}{\partial \tau}=\frac{a(c-b)}{\lambda_{R}}\left(\pi-\bar{\pi}_{\min }\right), \quad \frac{\partial C^{*}}{\partial \tau}=\frac{b(c-1)}{\lambda_{R}}\left(\pi-\bar{\pi}_{\text {min }}\right) \\
& a-b=\frac{(c-1) b^{2}-b+c}{b(c-1)}=\frac{1-\sqrt{1-4 a c+4 c}+1}{b(c-1)}
\end{aligned}
$$


when $\mathrm{c}-1 \neq 0, \sqrt{1-4 a c+4 c}+1 \neq 0$

$a-b=1+b+\frac{c}{b}(b-1)+\frac{c^{2}}{b}(b-1)$

Lemma 5: Equivalence between $L$ and $C$ is impossible in our model, ensuring the existence of a relatively more productive compliance sector.

This statement naturally follows from the previous illustration. Equation (30) has one and one feasible solution at $(c=1.2, b=2.4)$. Such a solution means that when complementarity rises between $\mathrm{C}$ and $\mathrm{L}$ (a condition necessary if the two sectors eventually become perfect substitutes), consultant's productivity comes in at twice their payments. That mans that in-house lawyers must earn a higher wage (by the factor exhaustion theorem). At that point, $\mathrm{a} \approx 5.4$. Lawyer's productivity must come to double the compliance consultants' productivity in order for lawyer and compliance consultant employment to change equally as they become better substitutes. Even from this simple example, we see that in our model's structure - lawyers and compliance consultants can never achieve perfect substitutability with $w=c, b=a$ and when $\theta=\gamma$.

Our findings conform with real-world observations. Scholars like Rebitzer and Taylor (1995) documented lawyer's excessively high wages a long time ago. In practice, inhouse lawyers assume part of the commercial risks of their employers, meaning they demand higher pay for higher risks that flat-fee external compliance advisors. ${ }^{16}$ Even a moment's reflection notes that external compliance advisors must have higher productivity than in-house advisors, otherwise financial firms would not hire them. Our model also predicted Sako et al. (2013) findings about lawyer contracting in Fortune 500 firms - many like JP Morgan and Bank of America are financial services firms. They find that firms prefer to hire external counsel unless some compelling complementarity or synergy in the firm makes hiring in-house counsel more attractive. In the language of our model, $L / C$ rises when $\gamma$ and a increase more than proportionally with changes $b$ and $\theta$.

Corollary 3: As the differences in wages and productivities between lawyers and compliance consultants shrinks, $\left.L^{*}-C^{*}=W\left[\tau\left(\pi-\bar{\pi}_{\min }\right)\right)\right]-\left[\psi c \lambda_{\pi}(c-1)\right]-\left[\lambda_{R} R(1-c)\right]$.

We can show that lawyer-consultant equivalence can not hold from another angle. We can make their factor payments and productivities vary only by discrepancy factor $\psi$ and then look at the effect of hiring as that discrepancy factor shrinks. Let's flip equation (22) (so the number of in-house lawyers appears in the numerator), and assume that $\mathrm{a}>\mathrm{b}, \mathrm{w}<\mathrm{c}$ and $a=\psi b$ and $w=\psi c$. We use the simple solutions for $\mathrm{L}$ and $\mathrm{C}$ we found in equations (10) and (11) rather than in equations (15) and (16) in order to illustrate the intuition without becoming bogged down in math. After introducing the wedge $\psi$, equation (32) shows how many more in-house lawyers financial firms would hire relative to outsourced

\footnotetext{
${ }^{16}$ Polinsky and Rubenfeld (2003) argue that such a risk-reward sharing arrangement would help align incentives, ensuring that lawyers work in their clients' best interest. An employment contract clearly gives lawyers higher powered incentives than employment as an external law firm. Such an arrangement also raises their productivity significantly above a hourly-rate compensation scheme.
} 
compliance professionals. Equation (33) simply rearranges the previous equation, combining relevant terms. Equation (34) looks at how financial firms' lawyer to consultant headcount changes as the wedge between their relative payments and productivities changes.

$$
\begin{aligned}
& \left(L^{*}-C^{*}\right)=\frac{\psi(c-b)\left[\tau\left(\pi-\bar{\pi}_{\min }\right)-\left[\psi c \lambda_{\pi}(c-1)\right]-\left(\lambda_{R} R\right)\right]-(c-1)\left[\tau\left(\pi-\bar{\pi}_{\min }\right)+\psi c \lambda_{\pi}(c-1)+c \lambda_{R} R\right]}{\tau} \\
& \left.\left.L^{*}-C^{*}=W\left\lfloor\tau\left(\pi-\bar{\pi}_{\min }\right)\right)\right]-\left[\psi c \lambda_{\pi}(c-1)\right]-\left[\lambda_{R} R(1-c)\right]\right] \\
& \text { where } W=\frac{((\psi(c-b))+((1-c)))}{\tau} \\
& \left.\left.\frac{L^{*}-C^{*}}{\psi}=\frac{(c-b)}{\tau}\left[\tau\left(\pi-\bar{\pi}_{\min }\right)\right)\right]-\left[\psi c \lambda_{\pi}(c-1)\right]-\left[\lambda_{R} R(1-c)\right]\right]-W\left(c \lambda_{\pi}(c-1)\right) \\
& \text { C-cost Sako cost regulation } \\
& \text { premium effect effect effect }
\end{aligned}
$$

The difference between in-house lawyer hiring and outside consultant hiring basically consists of three effects. The term $\tau\left(\pi-\bar{\pi}_{\min }\right)$ measures the extent of profits brought from complementarities between types of compliance advisors. The second term looks at external compliance consultants' costs and the reverberation on profits. The third term looks at the effect of money not spend on compliance consultants dedicated to dealing with regulation. What happens with the wedge between in-house lawyers' pay and productivity and their external compliance peers melts away? Equation (35) shows the difference between lawyer and consultant hiring depends on firms' profit levels and the extent of regulation. Lawyers and compliance consultants are not functionally equivalent in our model due to profit (Sako) and regulation effects. ${ }^{17}$

$$
\left.\left.\lim _{\psi \rightarrow 0} L^{*}-C^{*}=\frac{(1-c)}{\tau} \llbracket\left[\tau\left(\pi-\bar{\pi}_{\min }\right)\right)\right]-\left[\lambda_{R} R(1-c)\right]\right]
$$

As the wedge between lawyers and compliance consultants shrinks, compliance consultant fees reflect profit and regulation effects. Equation (36) shows that $c$ approaches the way the regulations change profits and the way they change profits when the theoretically improbably $\mathrm{C}=\mathrm{L}$ occurs. When $\mathrm{L}>\mathrm{C}$, c gets "twisted" by $\sqrt{-\frac{4 \lambda_{R} R}{\tau}\left(L^{*}-C^{*}\right)}$, reflecting the way that lawyers and compliance consultants differentially affect the way regulations affect financial firms' profits.

$$
\lim _{\psi \rightarrow 0} c \begin{cases}\frac{\lambda_{R} R-\tau\left(\pi-\bar{\pi}_{\text {min }}\right)}{\lambda_{R} R} & \text { when (L - C })=0 \\ \rightarrow \frac{2 \lambda_{R} R-\left(\pi-\bar{\pi}_{\text {min }}\right) \tau \pm \sqrt{-\frac{4 \lambda_{R} R}{\tau}\left(L^{*}-C^{*}\right)+\left(\pi-\bar{\pi}_{\text {min }}\right)^{2} \tau}}{2 \lambda_{R} R} & \text { when }(\mathrm{L}+\mathrm{C})>0\end{cases}
$$

\footnotetext{
${ }^{17}$ Sako effects refer to the empirical findings of Sako et al. we cite earlier.
} 


\section{Hiring compliance services in a competitive landscape}

What does competition among financial services firms and among legal services providers mean for the hiring and profitability of compliance outsourcing? Competition means that financial services firms would seek to maximise compliance service providers' productivity or decrease payments $w$ and $c$. As immediately obvious, higher profits will accrue to the firm which has higher productivities for $a, b, \gamma, \theta$, or lower $w$ and/or $c$. In our model, we show that financial firms will hire the "best" compliance advisory firm (with the highest productivity). We also show that in-house lawyers basically act like risk and innovation adverse copy-cats - waiting for innovations from external compliance consultants. They copy (with a lag) these innovations, along with the other compliance consultants who didn't think of the innovation. To start our discussion, we consider the reasons why firms prefer external compliance consultants.

\section{Compliance advisors' productivity in comparative perspective}

Lemma 6: Firms which prefer to hire compliance consultants over in-house lawyers will have higher profits by $\lambda_{R} \frac{b}{\vartheta} C^{\vartheta}-\frac{\lambda_{R}}{\gamma} L^{\gamma}+(R Q) a^{-\alpha R}$.

Equation (37) shows the effect on profits of increasing the productivity of in-house counsel (on the left-hand side) and outsourced compliance staff (on the right-hand side). For an equal productivity improvement $\Delta \mathrm{a}=\Delta \mathrm{b}$, under our modelling strategy, in-house will always have a natural disadvantage. In-house counsel has such a disadvantage occurs because in-house lawyer's productivity leads to costs internalized by the firm. As such, firms are indifferent to using in-house lawyers or outside compliance advisors only when in-house lawyer productivity is significantly higher than external compliance advisors. As shown in equation (38), after simply setting $\mathrm{C}=\mathrm{L}$, in order for lawyers' productivity must equal compliance advisors productivity scaled by the cost parameter $\alpha$ (as applied over the volume of regulation $R$ ).

$$
\frac{d \pi}{d a}=\frac{\lambda_{R}}{\gamma} L^{\gamma}-(R Q) a^{-\alpha R}
$$

lawyer productivity profit effect

$$
\frac{d \pi}{d b}=\lambda_{R} \frac{b}{\vartheta} C^{\vartheta}
$$

How much more productive do in-house lawyers need to be in order to affect firm profits the same way as external compliance consultants? Equation (38) shows the condition under which $d \pi / d a=d \pi / d b$. At that point, a change in either groups' productivity has the same effect on profits. As shown, in-house lawyers' productivity needs to increase by a relatively large factor to get the same profit punching power as compliance consultants. We can be reasonable sure that $\mathrm{a}<<\mathrm{b}$ as $R Q$ will represent a relatively large number, $\alpha \mathrm{R}$ represents a small number. Even if we do not know the values for $\gamma$ or $L$, we know these terms only make $a$ smaller relative to $b$. Such a result leads us to corollary 4 . 


$$
a=\left[\frac{\lambda_{R}}{R Q}\left[\frac{b}{\vartheta} C^{\vartheta}-\frac{\lambda_{R}}{\gamma} L^{\gamma}\right]\right]^{\alpha R}
$$

Corollary 4: To achieve a similar increase in profits, any change in external compliance firms' productivity requires an increase of in-house counsel's productivity by $\frac{d a}{d b}=\left[\frac{\alpha \lambda_{R} C^{\vartheta}}{\vartheta Q}\left[\frac{b}{\vartheta} C^{\vartheta}-\frac{\lambda_{R}}{\gamma} L^{\gamma}\right]\right]^{\alpha R-1}$ and wage growth of $\frac{d w}{d a}=\frac{a^{-\alpha R} Q-\lambda_{R} \frac{1}{\gamma} L^{\gamma}}{\lambda_{\pi} L}$.

What do we know about in-house counsel and their productivity in our model? According to the way competition drives innovation, financial firms have no incentives to invest in costly and risky in-house programmes aimed at increasing in-house lawyers' productivity. Their optimal strategy consists of waiting until an innovation occurs in the external compliance sector. Once that occurs, equation (39) tells us how much in-house counsel's productivity changes (by differentiating equation (38)). Equation (28) provides the condition when in-house lawyers' represent perfect substitutes for outside compliance advisors (and visa-versa).

Such a corollary relies on several styled facts about in-house counsel. First, in-house lawyers' labour must provide a relatively undifferentiated stock of services. If they could differentiate themselves beyond commodity providers, an outside compliance option would not exist. Second, lawyer movement between financial service firms shows the relative similarity of activities in these companies. If tasks in various financial service firms were very highly specialised and difficult, such movement would prove very difficult. Third, folk wisdom tends to view in-house counsel as innovation-stifling. ${ }^{18}$ While not necessarily buying this myth, we use it as the basis (right or wrong) of our assumption that compliance innovations come from outside the financial firm.

Corollary 5: Financial firms will always prefer to buy compliance cost-saving innovations from $C$ rather than hire (at the margin) external compliance companies, meaning that they will drive innovation for the entire financial services compliance advising sector.

To prove that external compliance consultants drive regulatory innovation, we need to show that $\mathrm{d} \pi / \mathrm{d} b>\mathrm{d} \pi / \mathrm{d} a$ and $\mathrm{d} w / \mathrm{d} a>\mathrm{d} c / \mathrm{d} b$. If this condition holds, then financial firms will obtain larger profits from "taking" innovations from $C$ rather than L. ${ }^{19}$ Lemma 6 shows that $\mathrm{d} \pi / \mathrm{d} b>\mathrm{d} \pi / \mathrm{d} a$. What about $\mathrm{d} w / \mathrm{d} a>\mathrm{d} c / \mathrm{d} b$ ? The easiest way to show this consists of

\footnotetext{
${ }^{18}$ Naturally, no rigorous academic studies have attempted to show whether in-house counsel does stifle innovation. For some views on the debate, see Kevin O'Keefe, How risk-averse lawyers stifle innovation, available at: http://outofthejungle.blogspot.hk/2007/11/how-risk-averse-lawyers-stifle.html. For a contrary view, see John Wallbillich, Risk Averse In-House Counsel And Other Myths, avaiilable at: http://www.wiredgc.com/2011/05/13/risk-averse-in-house-counsel-and-other-myths/

${ }^{19}$ It would also help if we could prove that $\mathrm{L}$ is more risk averse than $\mathrm{C}$ and that the stylized facts show that in-house lawyers rarely create new ways of complying with new regulations. Such a proof would take too long in the confines of our model. So we consider our exposition as a partial proof.
} 
equation (28). ${ }^{20}$ When lawyers and external compliance consultants have exactly the same productivities and costs, we know - by differentiating equation (28) that $\mathrm{d} w / \mathrm{d} a>\mathrm{d} c / \mathrm{d} b$ only when $\mathrm{L}^{\gamma-1}>\mathrm{C}^{\theta-1}$. We already showed that $\mathrm{L}>\mathrm{C}$ for financial firms both in theory and in practice. Thus financial firms will always prefer to buy compliance innovation (in the confines of our model) rather than develop it. Thus, in-house counsel increases its productivity through its interaction with outside compliance service providers.

\section{Financial firm competition and compliance productivity growth}

How do firms compete in our model? With i and Q fixed (determined outside of the model), financial firms can compete only by changing pay and productivity. We could specify how firms could use profits to invest in enhancing compliance productivity, or specifying a bargaining function used to drop w and c. Let's choose an easier modelling strategy. Imagine a continuum of compliance consultants and their productivities described by equation (39). Think of these compliance advisors lined up along a continuum, with the first in the series having the lowest productivities (and thus lowest value-for-money). ${ }^{21}$ The second company has the second lowest productivity and so forth. In this formulation, $\mathrm{C}_{2}$ is better than $\mathrm{C}_{1}$ (and we denote this by the sign $\succ$ ). Think of the line of these compliance companies extending into a mist-filled area, as new firms emerge "from the mist" with better compliance techniques.

$$
\mathrm{X}_{k}=C_{1}\left(b_{1}, \vartheta_{1}, c_{1}\right) \prec C_{2}\left(b_{2}, \vartheta_{2}, c_{2}\right) \prec C_{3}\left(b_{3}, \vartheta_{3}, c_{3}\right) \prec \ldots
$$

We model the creation of new compliance innovations as follows. A new compliance consulting company emerges from the misty part of the continuum with probability $\rho$. In this case, $\rho$ equals the fixed probability of inventing a new technique which either raises productivity or lowers costs at any point in time. Each innovation increases profits by a fixed amount $\delta$. As shown in equation (38), we do not care whether the increase comes from the ability to produce more pages of compliance or from a drop in payments to compliance providers - or both. We can think of the shock as increasing $b$ to $b$ ' and working its way through several variables. As shown in equation (40), the benefits of such change over time lead to $\rho \delta t$. If no innovation occurs, then $\pi_{t+1}=\pi_{\mathrm{t}}$.

$\mathrm{E}\left[\pi_{\mathrm{t}+1}\right]=\rho\left(\pi_{\mathrm{t}}+\delta\right)$, for $\operatorname{prob}\left[\mathrm{b}_{\mathrm{t}+1}=\mathrm{b}^{\prime}\right]=\rho$

What is the profit growth from such an innovation? Equation (40) shows the total effect of an innovation shock condition for compliance consultants' productivity. Acting

\footnotetext{
${ }^{20}$ Equation (28) shows the condition we called lawyer-consultant equivalence.

${ }^{21}$ Imagine that pay is fixed in the short-run or determined in a larger compliance market, so that determination of compliance companies' productivity determines their value for money. In other words, financial firms can not choose indifferently between a low $\mathrm{c}$ and low $\theta / \mathrm{b}$ and a high $\mathrm{c}$ with a high $\theta$ and $\mathrm{b}$. We describe $\mathrm{C}_{2}$ as "better" than $\mathrm{C}_{1}$ in the next sentence to avoid discussing whether they have a higher productivity or lower cost.
} 
through the $\mathrm{C}$, c, and a channels (and we describe why the a-channel in a bit). ${ }^{22}$ To keep the model simple, we do not vary $\theta$ and $\gamma$. The first term looks at the way changes in compliance consultant's productivity affects profits via consultant employment. The second term looks at the way productivity changes in $b$ affect productivity changes in a. The third term looks at the way changes in consultants' fees affect profits. These fees might go up (reflecting increased productivity) or down (reflecting the increased effective "supply" of compliance staff). The final term reflects a "direct effect" through a lessbinding regulatory constraint.

$$
\begin{aligned}
& \delta=\frac{d \pi}{d b}=\overbrace{\left(\frac{\left(\lambda_{R} b C^{\vartheta-1}-\tau \cdot L-\lambda_{\pi} c\right)\left(-\pi_{b}-\frac{\lambda_{R}}{\vartheta} C^{\vartheta}\right)}{\pi_{C}-\tau \cdot C+\lambda_{R} b C^{\vartheta-1}-\lambda_{\pi} c}\right)}^{\left(\frac{\partial \pi}{d C} \frac{\partial C}{d b}\right)} \\
& +\overbrace{\left(\frac{-\pi_{b}-\lambda_{R} \frac{1}{\vartheta} C^{\vartheta}}{-\pi_{a}(1-\alpha) R a^{(1-\alpha) R} Q+\lambda_{R} \frac{1}{\gamma} L^{\gamma}}\right)}^{\left(\frac{\partial \pi \partial a}{\partial a}\right)}+\overbrace{\left(\frac{\left(-\lambda_{\pi} C\right)\left(-\pi_{b}-\frac{\lambda_{R}}{\vartheta} C^{\vartheta}\right)}{\pi_{c}-\lambda_{\pi} C}\right)}^{\left(\frac{\partial \pi}{\partial c} \frac{\partial c}{\partial b}\right)}+\overbrace{\lambda_{R} \frac{1}{\vartheta} C^{\vartheta}}^{\frac{\partial \pi}{\partial b}}
\end{aligned}
$$

In order to get in-house lawyer productivity moving, we can assume that regulatory innovations "leak" across the boundaries of the firm, from the $C$ working at financial firms to $L .{ }^{23}$ Equation (41) shows the way that the higher level of $a$ affects the change in profits. The equation simply adds equation (38) to corollary 4 to find $a$ 's effect on profits from equation (40). As we show in the next section, these changes in profits determine the extent to which regulators can increase regulations. Yet, if we want to model the way a changes over time, we can simply plug the new value of $b$ into equation (38) - as shown in equation (42). By integrating over time, as shown in equation (43), we obtain an expression for the way that in-house lawyers' productivity grows over time due to the competition between financial firms which drives outsourced compliance consultants to innovate.

$$
a^{\prime}=\left[\frac{\lambda_{R}}{R Q}\left[\frac{b}{\vartheta} C^{\vartheta}-\frac{\lambda_{R}}{\gamma} L^{\gamma}\right]\right]^{\alpha R}+\left[\frac{\alpha \lambda_{R} C^{\vartheta}}{\vartheta Q}\left[\frac{b}{\vartheta} C^{\vartheta}-\frac{\lambda_{R}}{\gamma} L^{\gamma}\right]\right]^{\alpha R-1}=\left(\frac{-\pi_{b}-\lambda_{R} \frac{1}{\vartheta} C^{\vartheta}}{-\pi_{a}(1-\alpha) R a^{(1-\alpha) R} Q+\lambda_{R} \frac{1}{\gamma} L^{\gamma}}\right)
$$

original level of a increased by da/db change in profits $(\mathrm{d} \pi / \mathrm{da})$

$$
\dot{a}=\left[\frac{\lambda_{R}}{R Q}\left[\frac{\rho b^{\prime} t}{\vartheta} C^{\vartheta}-\frac{\lambda_{R}}{\gamma} L^{\gamma}\right]\right]^{\alpha R}
$$

\footnotetext{
${ }^{22}$ To give a prelude, we vary profits by the way $b$ changes $a$ because we will argue for diffusion of the innovation from $\mathrm{C}$ to $\mathrm{L}$.

${ }^{23}$ Several studies note that such learning represents a key vector by which firms import legal and compliance innovations (Allen \& Overy, 2012).
} 
$a(t)=\frac{1}{\alpha R+1}\left[t-\frac{\lambda_{R}}{\gamma} L^{\gamma}\left(\frac{\lambda_{R}}{R Q}\left(t-\frac{\lambda_{R}}{\gamma} L^{\gamma}\right)\right)^{\alpha R}\right]+k$

\section{The Interaction between Regulation and Compliance}

Regulators do not sit still. In our model, we view regulators as regulation-maximisers. Such a view of regulators may not be as bad it sounds. Acharya (2009) argues that regulators want to minimize systemic risk by having banks take into account the riskiness of others' investment as well as its own - and the covariance between investments. Other authors refer to regulations governing leverage, capital adequacy and issues brought to the fore in new legislation like Dodd-Frank and the relevant EU legislation (Brunnermeier and Sannikov, 2014; Goodhart, 2005). Yet, a glance at our model (as shown in Equation (47))shows why modelling the complexity of rulemaking as simply viewing the "stock" of R rising. In our model, as the stock of regulation rises, more compliance staff are needed. The reason for such regulations is relatively irrelevant. We don't need to model private or public risks. We only need to keep an eye on the stock of regulation to know what is happening in the wider economy. Similarly, for capital reserves, risk-adjusted capital adequacy, and other rules, their effect consists of raising the $\pi_{\min }$ in our model. These rules increase the amount of capital financial service firms must hold. In our simple model, this requires increasing profits (or spending less of them on compliance and other staff). In any case, simply raising $\pi_{\min }$ has the same effect as creating that wedge or buffer. The main point remains: regulators will maximise regulation subject to financial firms' profit and manpower constraints.

Imagine that regulators want to maximise regulation - under the view that more regulation leads to decreased systemic risk and other harms. If regulators maximise equation (8) with respect to regulation $\mathrm{R}$, then the shadow price of this regulation on profits will equal the level of financial services provided $\mathrm{Q}$, adjusted for in-house counsel's productivity. Growing regulations significantly hurts financial firm profits. ${ }^{24}$ As shown more clearly by equation (44), regulation clearly changes as a function of the compliance productivity of in-house counsel. Equation (45) shows how $\mathrm{R}$ changes in response to changes in such productivity in the static case (before considering how such productivity changes in response to increasing productivity in the compliance sector).

$$
\begin{aligned}
& \lambda_{R}=\left[-\ln (a) a^{(1-\alpha) R}\right] Q \\
& R=\frac{\ln \left(-\lambda_{R}\right)-Q-\ln (a)}{(1-\alpha)(\ln a)}
\end{aligned}
$$

\footnotetext{
${ }^{24}$ The term - $\ln (\mathrm{a})$ in particular looks almost like a utility curve, sloping downward and going negative at 1.
} 
What does our model suggest about the effect of financial regulation on financial service firms' profitability? We know from the extant literature that such an effect would be extremely tenuous at best (Barth et al., 2003). Our model matches this empirical observation. Going back to equation (8), differentiating firms' profits with respect to regulation results in equation (46). As shown in equation (47), such profitability declines only for a relatively low level of regulation. Figure 5 shows the regions over which profits increase and decrease for various levels of $\mathrm{R}$ and $\mathrm{Q}$. Let's recall that $\mathrm{R}$ would likely vary between 0 and 1 . If we thus wanted/expected a service level provision of $Q=5$, then $R \approx \mathrm{e}^{-3}$ or $R=.05$ (roughly the level of France if we use the measure shown in Appendix I).

$$
\begin{aligned}
& 0>\frac{\partial \pi}{\partial R}=\left[\ln (a) a^{(1-\alpha) R}\right] Q-\lambda_{R} \\
& R<a(1-\alpha) \sqrt{\frac{\ln \left(\lambda_{R}\right)}{\ln (\ln (a)) \ln (Q)}}
\end{aligned}
$$

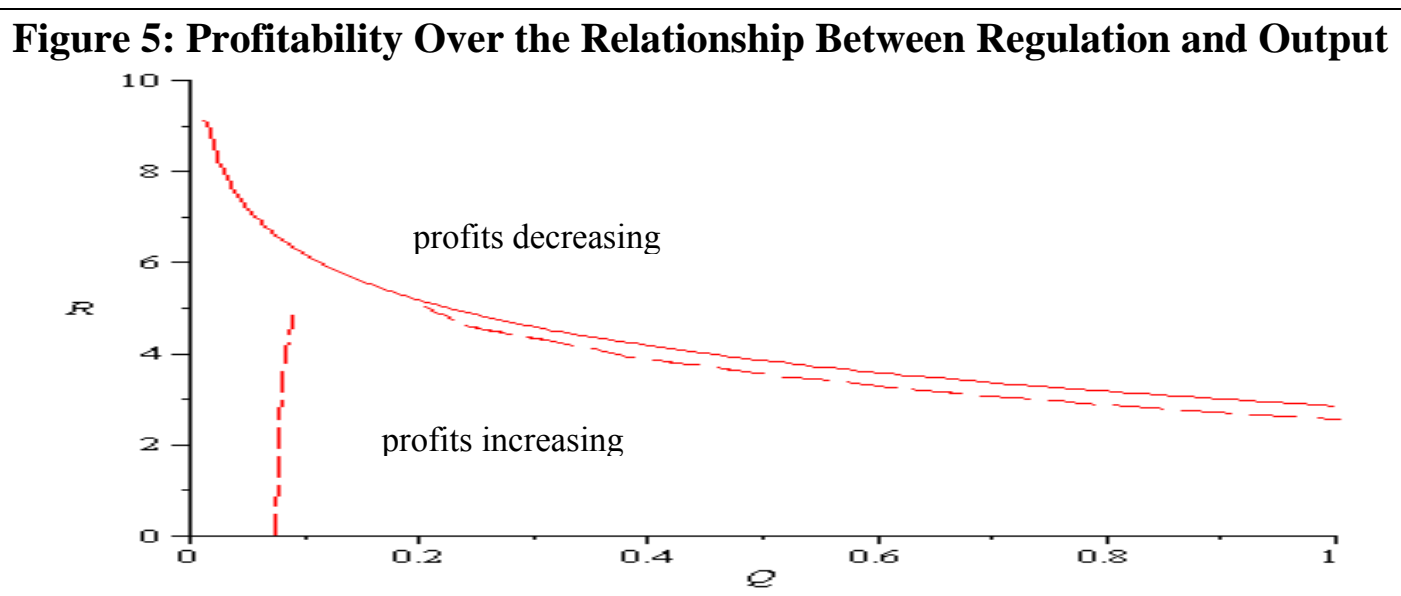

The figure shows the relationship between regulation and output given the model described in the paper. We set $(\alpha-1)=1$ and $\lambda_{R}=6$ and $a=2$ for the purposes of this simulation.

Lemma 7: Regulation and increasing quantities of service provision are locked in an inexorable march forward such that $Q>\frac{\lambda_{R}}{\ln (a) a^{(1-\alpha) R}}$ and $Q>\frac{\pi_{r}+\lambda_{R}}{\left(i-\ln (a) a^{(1-\alpha) R}\right)}$

Before we look at the effect of regulation on compliance advisor hiring, we need to know the effect on overall financial services. Regulators have two basic constraints. First, the no profit rule says that regulators will crank up regulations up to the point where firms will not make profits. If $d \pi / d R>0$, then $R<R^{*}$ (where $\mathrm{R}^{*}$ represents regulator's preferred level of regulations). If $d \pi / \mathrm{dR}<0$, then $\mathrm{R}>\mathrm{R}^{*}$ and excess regulations choke off potential extra resources usable to comply with more regulations later. Second, the consumer 
amenity rule says that regulators will not want to chock off the provision of financial services Q. As such, regulators can choose any regulatory level such that $d Q / d R>0$. Equation (46) provides the basis for the first part of lemma 7. Regarding the second part, we can use the implicit differentiation theorem on equation (8) in order to arrive at equation (48). From there, rearranging terms provides the second part of lemma 7. Both parts of lemma 7 strictly imply that the level of regulation and financial services grow (or shrink) together.

$$
0<\frac{\partial Q}{\partial R}=\frac{-\pi_{r}+i Q-\ln (a) a^{(1-\alpha) R} Q-\lambda_{R}}{-\pi_{q}+Q-\frac{1}{1-\alpha} a^{(1-\alpha) R}}
$$

What is the effect of an increase in regulation on hiring of compliance advisors in our simple model? We know that compliance spending increases when regulations increase if $\partial \mathrm{C} / \partial \mathrm{R}>0$. Equation (49) shows when this condition holds. Equation (50) shows after some manipulation while equation (51) shows the general solution for R. Understanding how so many variables and parameters vary as $\mathrm{R}$ and $\mathrm{Q}$ move can prove exceedingly difficult. Equation (52) shows the much simpler case when $(1-\alpha)=1$, so that much of the equation washes out. In this simple case, the level of regulations must ensure that the profit destroying effect of regulations does not overcome firms' ability to take on more compliance staff to deal with expanded regulations. As shown in equation (53), when the coefficient on a depends from 1 , we see - as we already saw in equation (45) -- that the regulation level also takes the amount of financial services offered into consideration. As an aside, the concave function W (or Lambert-W function) reflects diminishing gains from regulation.

$$
\begin{aligned}
& 0<\frac{\partial C}{\partial R}=\frac{\pi_{R}+\lambda_{R} R-\ln (a) a^{(1-\alpha) R} Q}{-\pi_{C}-\tau L-\lambda_{R} b C^{\vartheta-1}-\lambda_{\pi} c} \\
& -\pi_{R}<\lambda_{R} R-\ln (a) a^{(1-\alpha) R} Q \\
& R=\frac{-\lambda_{R} W\left(\frac{-a^{\frac{(1-\alpha) \lambda_{R}}{\lambda_{R}}}(1-\alpha) \ln ^{2}(a)}{\lambda_{R}}\right) Q+(1-\alpha) \lambda_{R} \ln (a)}{-\lambda_{R}(1-\alpha) \ln (a)}
\end{aligned}
$$

where $W$ is the product log function

$$
\begin{array}{ll}
R>\frac{-\pi_{R}}{\lambda_{R}} & \text { for } \mathrm{a}=1,(1-\alpha)=1 \\
R>\frac{.72^{R} Q-\pi_{R}}{\lambda_{R}} & \text { for } \mathrm{a}=2,(1-\alpha)=1
\end{array}
$$


Corollary 6: Increasing regulations will increase the level of compliance consultant staffing such that $C=q(R, Q / a, b, \gamma, \lambda, \theta, L)$.

From equation (17) we can depict equation (52) and from equation (49) we can depict (53). Basically, equation (52) says that compliance staffing depends on the level of regulation. Equation (53) says that regulations depend on the level of financial services offered. Ergo, compliance staffing depends on the amount of financial services that banks and other offer (in other words, their size).

$$
\begin{aligned}
C^{*} & =\exp \left[\frac{1}{\theta-1} \ln \left(-\frac{\mu \exp -(R \gamma \theta+\text { stuff })}{\lambda b}\right]\right. \\
R^{*} & =\frac{-\lambda_{R} W(\text { stuff }) Q+\text { morestuff }}{-\lambda_{R}(1-\alpha) \ln (a)}
\end{aligned}
$$

We need look no further than equation (8) to show the relationship between firm size and compliance staff hiring. Confirming our intuition from equations (54) and (55), equation (56) shows that $\mathrm{Q}$ does not enter into this differential equation (except through an indirect effect on profits). As such, the change in $\mathrm{C}$ depends on the amount of $\mathrm{C}$ the firm has already hired - but not on Q.

$\frac{d C}{d Q}=\frac{\pi_{Q}-i-\frac{1}{1-\alpha} a^{(1-\alpha) R}}{-\pi_{C}-\tau \cdot L \cdot-\lambda_{R} b C^{9-1}-\lambda_{\pi} c}$

The relationship between $\mathrm{C}$ and $\mathrm{Q}$ help us construct supply and demand graphs for compliance consulting services in several ways. First, regulations $\mathrm{R}$ "shift" out the way that $\mathrm{C}$ responds to $\mathrm{Q}$. We show why and how such shifting takes place in Figure 6 in the next section. Second, increasing costs of external compliance advisors increases C's response when financial firms increase quantities produced (and thus the volume of regulation they must comply with). Third, increased profits result in increased compliance activity (from the quantity produced channel) and decreased compliance activity (from the opportunity of not using not complementary, well substitutable inhouse lawyers). Equation (56) shows these effects - which we illustrate in Figure 6 below.

\section{Short-term and longer-term relationship between regulation and compliance}

What does compliance-related innovation and increasing regulation do to compliance markets? Innovation leads to increased supply of compliance services; whereas regulation needs to increased demand. Figure 6 shows the intuition of our math about the effect on the supply and demand for compliance services. Starting from equilibrium at point 1 , we can assume for compliance service providers that increases in $c$ lead to an increase in $C$ (and thus resources for innovation). The figure shows the usual upward sloping supply 
curve, which we do not model explicitly in this paper. ${ }^{25}$ For financial firms, increases in c lead to decreased use of compliance firms' services (following the usual budget constraint effects). A change in innovation results in an outward shift in compliance supply. Increases in regulation result in outward shifting demand - increasing compliance costs. The final equilibrium cost and level of compliance (noted as point 2) depend of the location and slope of these curves. The result comes to ever-more regulation and compliance capacity.

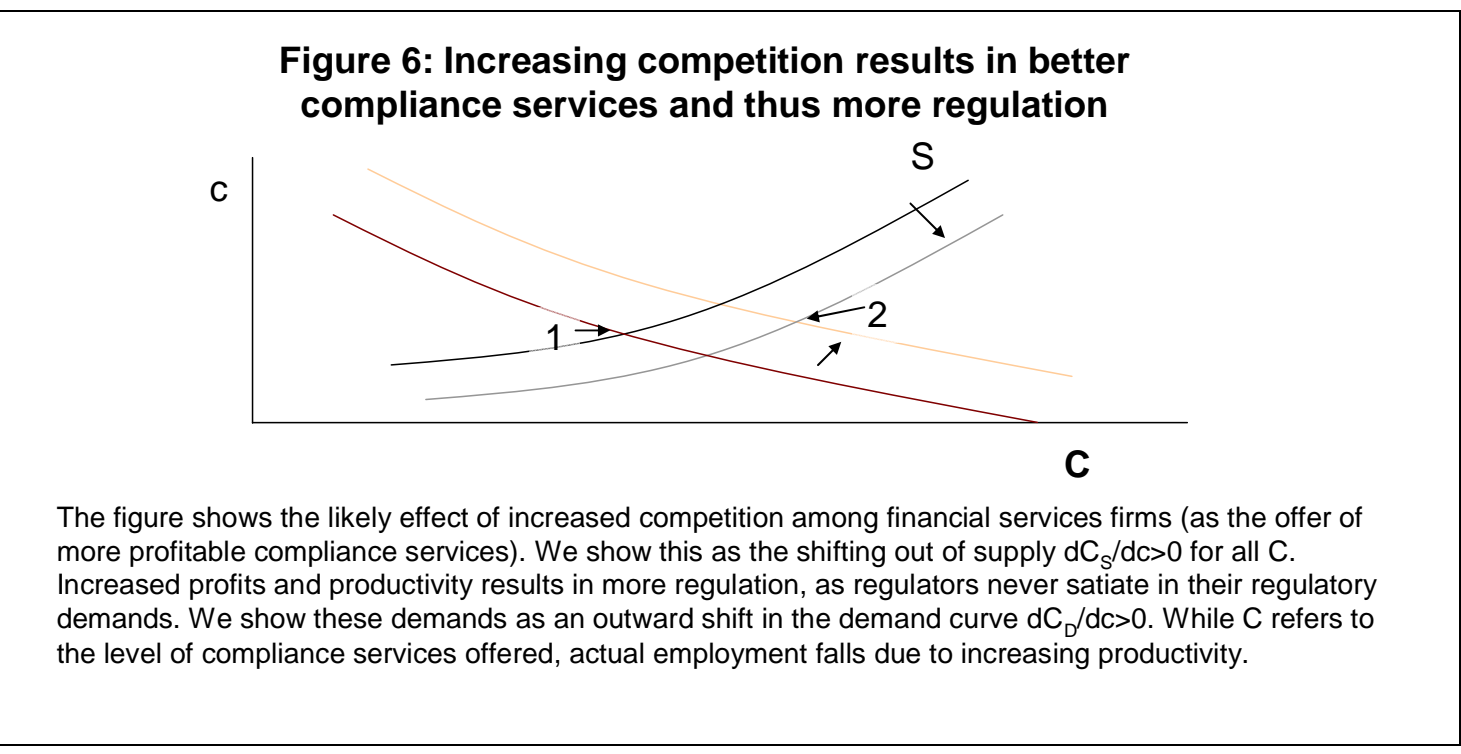

Lemma 7: Lawyer productivity increases over time such that time-contingent lawyer productivity equals $\dot{a}=\left[\frac{\lambda_{R}}{R Q}\left[\frac{\rho \delta t}{\vartheta} C^{\vartheta}-\frac{\lambda_{R}}{\gamma} L^{\gamma}\right]\right]^{\alpha R}$ and the level of regulation increases at the rate $\dot{r}=\delta \rho \frac{\left.\left(\ln (a) a^{(1-\alpha) R}\right] Q-\lambda_{R}\right)\left(\pi_{b}-\lambda_{R} \frac{1}{\vartheta} C^{\vartheta}\right)}{\frac{\lambda_{R}}{\gamma} L^{\gamma}-\left(\pi_{a}(1-\alpha) R a^{(1-\alpha) R}\right) Q}$

From the static case, we can speculate about how regulation and compliance activity respond to each other over time (inter-temporally). Recall from equation (42) - and its integral in equation (43) -- that lawyers' productivity grows over time, as a function of innovation shocks in the compliance sector. By integrating equation (23) we obtain inhouse lawyers' productivity, which increases as a function of time and the size of the firm's (or sector's) lawyer pool. More regulation in this formulation encourages more compliance activity, while simultaneously decreasing lawyerly productivity. ${ }^{26}$

\footnotetext{
${ }^{25}$ The reader can extend our model to explicitly allow for increases in $\mathrm{c}$ to affect $\mathrm{C}$. One obvious way consists of making the probability of a compliance innovation $\rho$ a function of changes in $c$. As c increases, the probability of an innovation increases, thus increasing $\mathrm{C}$.

${ }^{26}$ Such a decrease could stem of lack of familiarity with new rules or with a general vexation cost, which makes lawyers need to consult more pages of laws. In the simple version of our model, da/dR $=-(1-\alpha)$
} 
If lawyers' productivity increases as a function of time, then so must regulation. Equation (57) shows the way that regulations change over time. Regulations change as financial firms' profits change. These profits change as legal compliance advisors' productivity (both in-house and external compliance advisors') changes. Such productivity drifts upward over time at the rate $\rho t$. Equation (58) slightly rearranges the previous equation, to show how $\dot{r}$ represents a function of $\dot{b}$. Equation (59) finds the level of regulation for the upward drifting level of compliance productivity.

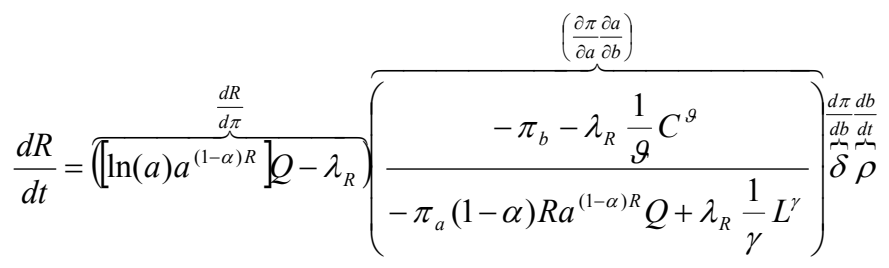

$$
\begin{aligned}
& \frac{d R}{d t} \equiv \dot{r}=\frac{\left.\left(\ln (a) a^{(1-\alpha) R}\right] Q-\lambda_{R}\right)\left(\pi_{b}-\lambda_{R} \frac{1}{\vartheta} C^{\vartheta}\right)}{\frac{\lambda_{R}}{\gamma} L^{\gamma}-\left(\pi_{a}(1-\alpha) R a^{(1-\alpha) R}\right) Q} \dot{b} \\
& R(t)=\frac{\rho b\left(\frac{-\pi_{a}(1-\alpha) R \rho b t^{(1-\alpha) R}}{\frac{\lambda_{R}}{\gamma} L^{\gamma}}-1\right)\left(\frac{\pi_{a}(1-\alpha) R \rho b t^{(1-\alpha) R}}{\frac{\lambda_{R}}{\gamma} L^{\gamma}}-\frac{1}{(1-\alpha) R}\right)}{\frac{\lambda_{R}}{\gamma} L^{\gamma} \pi_{a}(1-\alpha) R \rho b} \Phi t
\end{aligned}
$$

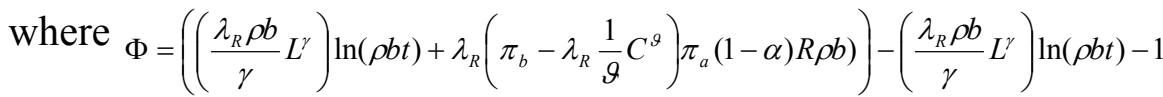

Do any economic factors encourage an equilibrium convergence in compliance innovations and regulation? Figure 7 shows the results of a supposition (and no more than that) for the equilibrium growth in compliance innovation and regulation. Under our assumptions, regulators want to increase the growth of regulations as compliance service providers offer the innovations needed for financial service firms to deal with them (shown as curve RR in the figure). The compliance services sector clearly has incentives to speed up investments in new advice and technologies for offering that advice as regulatory adoption speeds up (shown as curve $\mathrm{CA}$ ). In theory, regulators and compliance service providers should set the speed of their relevant activities to equal each other. 


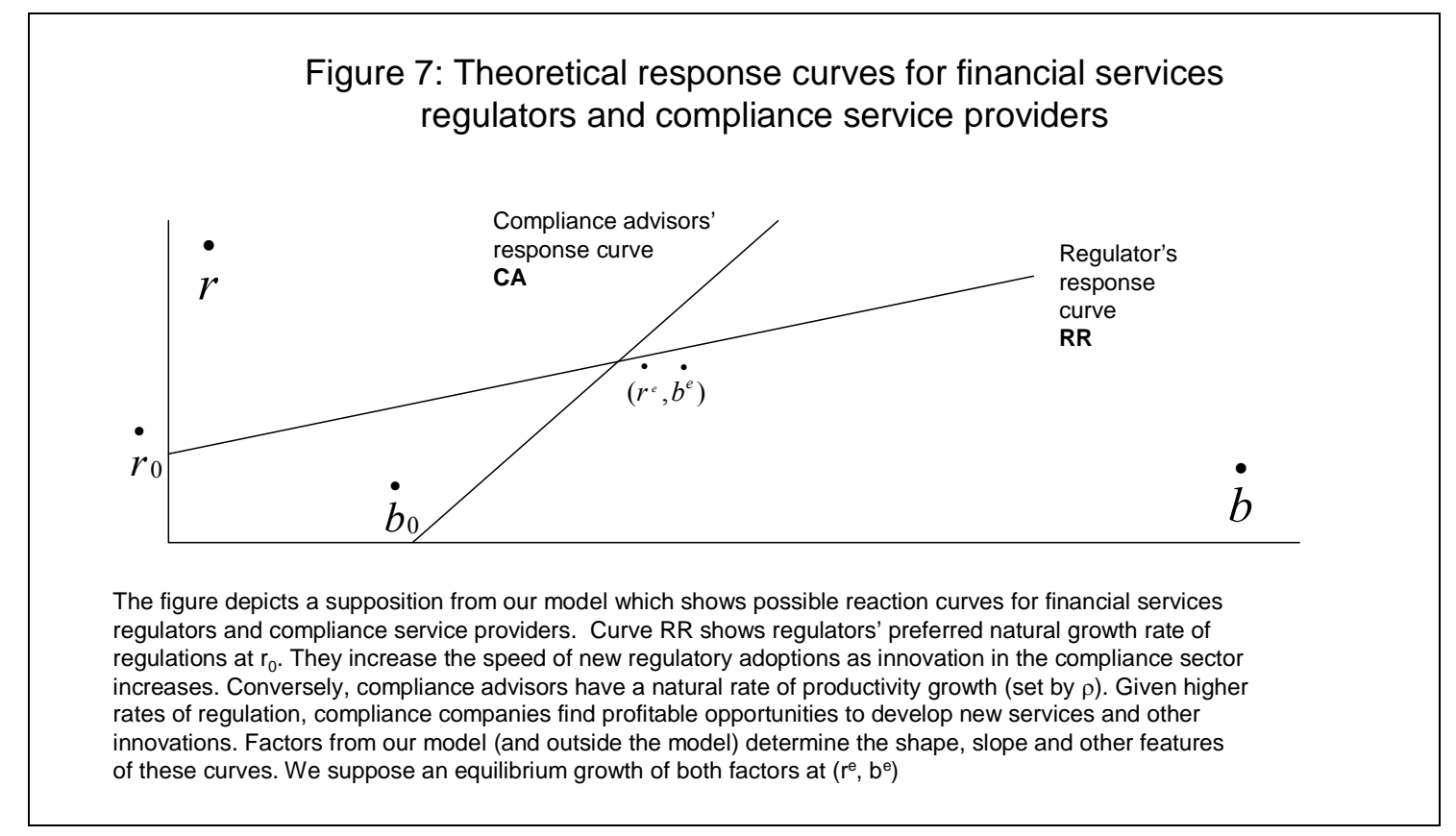

\section{Financial Centre Competitiveness}

What happens if regulators regulate "out of bounds" (namely under or over-regulating given the extent of compliance capacity among financial firms? If regulators overregulate in the short-term (anticipating future compliance productivity growth), such over-regulation hurts profits, thereby making financial services firms uncompetitive visa-vis foreign companies. If they under-regulate, they dull incentives needed to adopt costsaving compliance techniques - again hurting profits and competitiveness. ${ }^{27}$ Figure 8 shows the effect on financial firms' profits when regulators over and under regulate. Equation (60) shows the change in profits $(\Delta \pi)$, in-house lawyer employment $(\Delta \mathrm{L})$ and external compliance consultant employment $(\Delta C)$ when regulators under-regulate by

\section{$\mathrm{R}=\mathrm{R}-\zeta$. Counter-intuitively, legal advisor employment falls as regulation rises} (because profits fall).

$$
\left(\begin{array}{l}
\Delta \pi \\
\Delta L \\
\Delta C
\end{array}\right)=\left(\begin{array}{c}
\frac{a^{(1-\alpha) R}\left(a^{(R+\zeta)}-1\right)}{1-\alpha} Q+\left(\tau \cdot \frac{(\zeta \cdot c)(w \zeta)}{(a c-b w)^{2}}\right) \\
\frac{\zeta \cdot c}{a c-b w} \\
\frac{-w \zeta}{a c-b w}
\end{array}\right)
$$

\footnotetext{
${ }^{27}$ Such under-regulation also results in the well-known problems of increasing systemic risk and other social harms. We do not model these risks/harms in our model - thus we avoid any discussion of them.
} 
Figure 8: A Larger Compliance Sector Actually Makes Financial Services Firms More Profitable

$\pi$

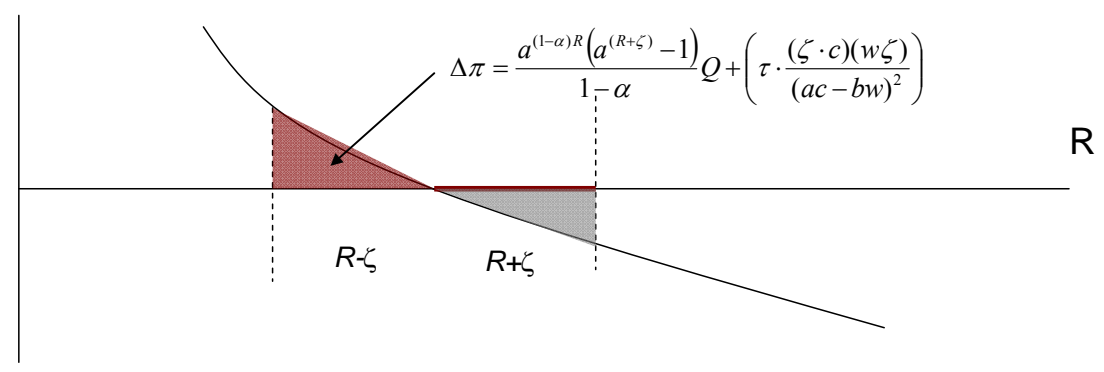

The figure shows the effect on profits - and thus on the amount of compliance-related Advisors (in-house lawyers and external compliance consultants) when the regulator over-and-under regulates. For under-regulation, the size of the compliance advisory sector RISES, reflecting more profits used for more advice. Such a result defies folk wisdom that more financial regulation represents a boon for lawyer-advisor employment.

So what happens to a jurisdiction whose regulators allow financial service providers the change to make profits? Instead of making compliance-related innovation occur at random, lets assume that such innovation depends on the resources allocated to the compliance sector. Namely, replacing $r$ in equation (40 leads to equation (61). Let's further imagine two jurisdictions - "Labuan" and "Singapore." Singapore has a higher C paid for from previous positive profits. As such, lawyer's productivity grows faster (as shown by the difference between equations (63) and (62). Recall from equation (37) that profits grow at $\frac{\lambda_{R}}{\gamma} L^{\gamma}-R Q a^{-\alpha R}$ for each change in $a$. Thus, for the same profit level, our hypothetical Singapore will have higher profits if the cost saving effect of compliance staff exceed their costliness at work.

$$
\begin{aligned}
& \mathrm{E}\left[\pi_{\mathrm{t}+1}\right]=\rho\left(\pi_{\mathrm{t}}+\delta\right), \text { for } \operatorname{prob}\left[\mathrm{b}_{\mathrm{t}+1}=\mathrm{b}^{\prime}\right]=\omega C^{-y} \mid 0<\rho<1 ; \quad 0<C<\omega^{\frac{1}{y}} \\
& \dot{a}_{\text {Labuan }}=\left[\frac{1}{R Q}\left[\omega C^{-y} b^{\prime} t .5 C-.5 L\right]\right]^{\alpha R}=\left[\frac{1}{R Q}\left[.5 \omega C^{1-y} b^{\prime} t-.5 L\right]\right]^{\alpha R} \\
& \dot{a}_{\text {Singapore }}=\left[\frac{1}{R Q}\left[\omega C 1^{-y} b^{\prime} t-L\right]\right]^{\alpha R}
\end{aligned}
$$

Jurisdictions which "invest" in compliance staff (and thus innovation) can achieve greater competitiveness through higher profits and lower costs. Figure 9 shows the trade-off between two hypothetical jurisdictions, which we have labelled as Singapore and Labuan. In the Singaporean case, a larger compliance sector leads to the higher profits we showed in the previous paragraph. For Labuan's regulation-to-profit trade off, a level of regulation $\mathrm{R}_{\mathrm{L}}$ corresponds to no profits (as shown at point 1). If Singaporean companies with their larger compliance staffing - enter the Labuan market, they would earn the profits shown by the purple triangle by expending the resources needed to comply with a much small stock of regulations. At point 3, they would earn no profits. Point 2 
shows the profits earned by these Singaporean financial services institutions if they had to comply with some global average level of regulation $\mathbf{R}$. For the moment, we can think of $\mathrm{R}$ as a common set of regulation promulgated by the Financial Stability Board or the growing "acquis communautaire" of financial regulation. If Labuan's regulatory agency increased regulations in this situation, they would bankrupt local financial services firms and cause foreign firms to have competitive advantage.

Figure 9: A Larger Compliance Sector Actually Makes Financial Services Firms More Profitable

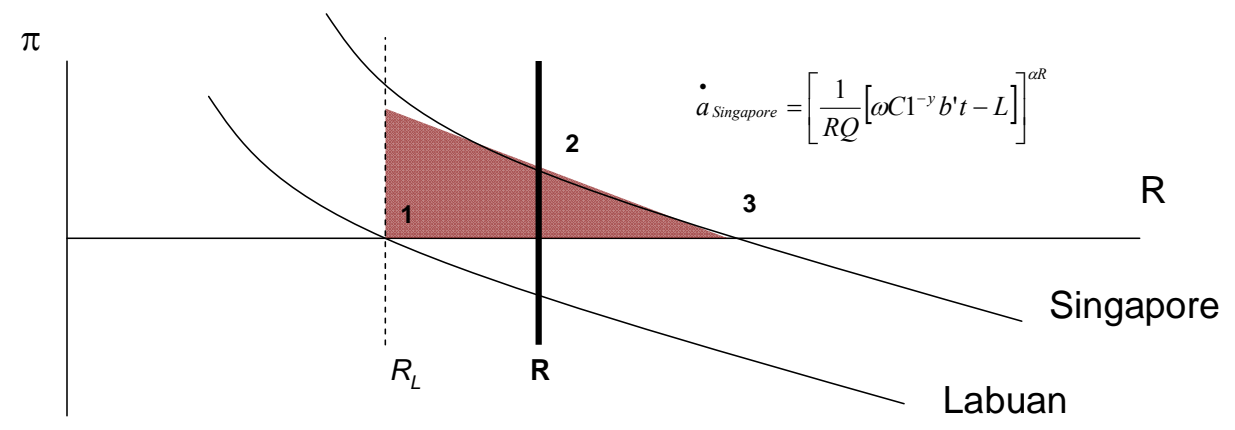

The figure shows the way that larger compliance employment in Singapore affects the trade-off between regulation and profits. Past profits went to hire more compliance staff, whose absolutely level encourages faster compliance productivity growth. Such faster growth - under certain circumstances - leads to more profits FOR EACH LEVEL OF REGULATION. As a result, for regulation and Labuan's level $\left(R_{L}\right)$, Singaporean companies can earn total profits denoted by the purple triangle. For an average regional level of regulation $\mathbf{R}$, Singaporean banks earn profits while Labuan banks lose profits. The figure thus shows how regulation can affect each jurisdiction's competitiveness.

$$
\frac{d \pi}{d C}=\left[\frac{\lambda_{R}}{\gamma} L^{\gamma}-R Q a^{-\alpha R}\right]\left[\frac{\lambda_{R} \alpha\left(\omega C^{-y} b^{\prime}\right)^{2}}{Q}\left[\frac{\rho b^{\prime} t}{\vartheta} C^{\vartheta}-\frac{\lambda_{R}}{\gamma} L^{\gamma}\right]\right]^{\alpha R-1} C^{\vartheta-1} t
$$

What happens to financial firms' profits and regulation as firms from heavily regulated jurisdictions compete with those from lightly regulated ones? Figure 10 shows a graphical version of the argument - which we use to save us from using constrained dynamic optimisation and make this already long paper longer. In this figure, we show Singaporean and Labuan financial firms constrained by a common set of regulations. Singaporean financial firms made a profit at this regulation level (thanks to larger compliance staffing). Labuan companies lose money, due to smaller compliance staffing. As Labuan companies lose money, they must fire compliance staff - reducing their productivity further. We show such productivity loss as shifting the Labuan $\pi$-R curve to the left. Point 5 represents the new break-even point for Labuan firms. 
Figure 10: A Larger Compliance Sector Actually Makes Financial Services Firms More Profitable

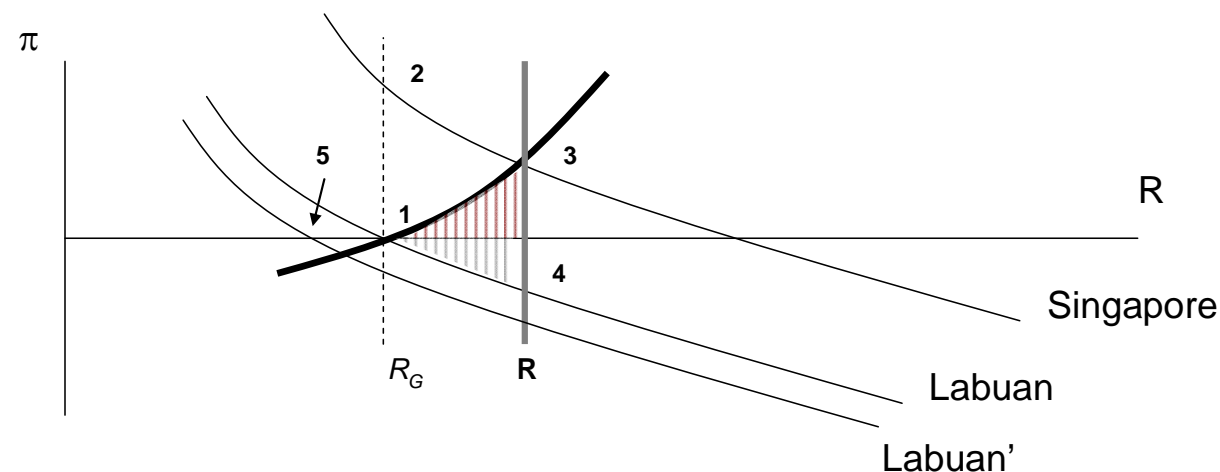

The figure shows the possible effect on financial service firms' profits of regulatory harmonisation. At point 1 , Labuan companies make no profits. Singapore financial firms would earn large profits noted at point 2 for this level of regulation. At a global or regional harmonised regulation level $\mathrm{R}$, Singapore financial firms would earn profits shown by point 3 while Labuan firms would lose profits as shown at point 4. Yet, negative profits mean a shrinking compliance sector for Labuan, further shifting in Labuan's $\pi$-R trade-off. Labuan will eventually need to isolate its banking sector and apply differential regulations.

Regulators' task consists of keeping regulations loose enough so that financial firms can earn the profits needed to expand their compliance departments, while still encouraging compliance-related innovation. Such a condition has entered into folk wisdom among bank regulators, in a version which we call the Menon Hypothesis. ${ }^{28}$ If the data show support for the hypothesis, then regulators play an important role in promoting the competitiveness of their financial services firms. ${ }^{29}$ In some cases, like in Hong Kong and Singapore, regulators need to slow down reform in order to give their financial firms time to become "compliance competitive" (Le Lesle et al., 2014). In other cases, they need to speed up reform to discourage market entry by financial firms at a compliance-cost disadvantage (Dobson and Kashyap, 2006).

Menon Hypothesis: If $\frac{\lambda_{R}}{\gamma} L^{\gamma}>R Q a^{-\alpha R}$, increased financial regulation leads to an increasingly internationally competitive financial services sector when $\frac{C^{\vartheta}}{L^{\gamma}}<R Q\left[\frac{\vartheta}{\gamma \rho b^{\prime} t}\right]$ and $\frac{\dot{\pi}}{\dot{r}}>0$

\footnotetext{
${ }^{28}$ The Menon Hypothesis comes from the Executive Director of the Monetary Authority of Singapore, who in 2001, argued for an expanded role for financial regulators on the grounds that such regulation actually helped improve financial firms' profitability. See Ravi Menon. (2001). Sound Regulation as a Source of Competitive Advantage. Speech at the Asian Banker Summit. Available online at: http://www.mas.gov.sg/news-and-publications/speeches-and-monetary-policystatements/speeches/2001/sound-regulation-as-a-source-of-competitive-advantage--21-mar-2001.aspx ${ }^{29}$ We present the theory in this paper, and discuss empirical issues in a subsequent (follow up) paper.
} 


\section{Policy Options for Regulators}

The data appear to support the spiralling interaction between regulators and financial services firms. Authors like Morrison and White (2009) shows that investors prefer "better regulated" (which in their formulation actually means more regulated) jurisdictions. Given our model, policymakers, financial services firms and their legal advisors have 5 options for dealing with the ever-spiralling interaction between competition, productivity and regulation. The first option (encouraging co-operation between compliance service providers) seems unlikely to succeed, while the other 4 options appear more fruitful.

Policy Option 1: Promote coordination between compliance firms themselves and with regulators

In our model, ever increasing compliance innovation leads to more regulation. Such a view echoes other scholars who have argued that regulators need to protect banks from themselves - and their excessive competition (Beck, 2008). Explicit agreements between compliance solutions providers would likely run foul of various countries' competition (antitrust) authorities. Compliance service providers could also meet with regulators, encouraging them to forgo increasing regulation. Such meetings would allow compliance service providers the opportunity to reduce the introduction of innovations below the $\rho t$ level, in case they worry regulators will over-regulate. However, regulators in most jurisdictions remain relatively isolated from market participants. Thus, this option appears exceedingly unlikely to work in practice.

Policy Option 2: Set up government-sponsored exchanges of compliance "best practice"

Compliance innovation occurs because such innovation results in a bump in financial service firm profitability. If regulators could somehow encourage the gains of such innovation, without encouraging the profitability such innovation engenders, then a regulatory response would be less forthcoming. The best strategy would consist of activities which break the link between $\dot{b}$ and $\pi$. Figure 11 shows the relevant variables in financial firms' profit equation and the way the sharing of best practice can forestall regulatory action.

\section{Figure 11: Best practices and its effect on financial firm profitability}

$\begin{array}{ll}\text { variable } & \text { Description } \\ \mathrm{w} & \begin{array}{l}\text { increasing } \mathrm{dw} / \mathrm{d} \pi \text { would decrease } \pi \text { and thereby make regulation less } \\ \text { affordable. Such changes can occur from increased lawyer productivity }\end{array} \\ & \begin{array}{l}\text { or simply increased bargaining power } \\ \text { increasing da/db would only work if wages rose, thereby decreasing }\end{array} \\ \mathrm{a} / \gamma & \begin{array}{l}\text { profits. So lawyer productivity needs to visibly increase. } \\ \text { increasing complementarity in our model has the effect of decreasing }\end{array} \\ \mathrm{c} & \begin{array}{l}\text { profits } \\ \text { Increased fees for compliance advisors helps keep down profits, and thus }\end{array}\end{array}$


firms' power to comply with expanding regulations.

$\alpha$ as structural regulatory burdens rise, such burdens help to keep profits down. A best-practice (like CSR) which everyone adopts will create a burden for all.

Q If compliance solutions help reduce financial firms' ability to offer services, this will keep down profits, thus discourage regulation.

Policy Option 3: Tie regulators' incentives to financial service firms' long-run, riskadjusted, Pareto-enhancing profitability

Regulation enters financial firms' profit maximisation function in two places - as a constraint determined by compliance resources and as a quantity-dependent cost. Regulation harms profits - thus regulators have to walk the knife-edge between encouraging and discouraging profits. They must simultaneously reduce profits as much as possible, while still not chocking off the profits that makes compliance possible at all.

Most financial regulatory authorities have no mandate for ensuring the profitability of the financial services they regulate. Most have the mandate to ensure an "orderly" market, however they define it. As Garten (1989) noticed almost 20 years ago, regulators' implicit support for banking profits in the pre-2008 period lead to a new regulatory approach. Even in banking's "deregulatory age", regulations continued to ratchet upward. Using the long-run, risk-adjusted profitability of the banking sector as a maximand (along with consumer surplus) would help prevent ever-spiralling regulation. Naturally, if regulators "help" banks earn more profits, such help shouldn't come at the expense of depositors, investors, other customers and so forth.

\section{Policy Option 4: Engage in regular regulatory guillotine exercises}

Following this option, regulators would periodically review regulations and eliminate unnecessary, repetitive and otherwise harmful regulation. In practice, much expansion in $R$ comes from regulatory experimentation. To the extent that regulators can achieve the same social outcomes with a lower R (and thus higher banking profits), they should do so. In practice, regulators probably care little about making regulations better. Regulators do not engage in "turf wars" which would make policy better (Weinberg, 2002). Competition between regulators would probably not lead to regulatory simplification particularly when regulators seek to expand their regulation to harmonize with foreign regulation in the era of "home run" regulation (Wilcox, 2005). Because regulators need a strong reputation for the various facets of their work, deregulation may not come swiftly... if at all (Boot and Thakor, 2006). A regulatory guillotine (or review and "chopping" of a wide-range of relatively useless regulations) would increase bank profitability significantly. Such a chopping - according to our model - would lead to large increases in lawyers' and compliance consultants' wages. ${ }^{30}$ Yet, such a move would discourage compliance innovation and anyway seems unlikely.

\footnotetext{
${ }^{30}$ Such a result stems from our first and second constraint, which requires the output of $\mathrm{C}$ and $\mathrm{L}$ and their factor payments to equal $\mathrm{R}$ and their factor payments to equal revenues.
} 


\section{Policy option 5: Encourage the pre-conditions for the Menon Hypothesis}

As postulated by the Menon Hypothesis, expanding financial regulation promotes the competitiveness of a financial centre's institutions if lawyers' productivity exceeds the cost of compliance $\left(\lambda_{R} / \gamma\right) L^{\gamma}>R Q a^{-\alpha R}$ and when financial regulation does not harm financial firms' abilities to earn the profits they need to hire compliance staff. Requiring nonlabour intensive methods of compliance can help boost lawyers' productivity. Encouraging regulations which do not scale (depending on the level of financial services offered) can also help. Tax incentives can also treat payments to in-house counsel and outsourced compliance consultants "better" than other business expenses. Such treatment may include providing tax credits for particular types of compliance activities.

\section{Conclusion}

The compliance industry looks like the clear-cut winner in regulators' drive to regulate their financial sectors. In this paper, we model the link between regulation and the demand for compliance consulting and related advisory services. In our simple model, we show how financial services firms' profits depend on the way they use in-house lawyers as opposed to (or in combination with) external compliance consultants. We show that compliance legal advisory can help reduce costs and boast financial service firms' profits in the short-run. In the longer run, competition among financial service firms leads to the emergence of new compliance solutions. These solutions lower compliance costs and thus allow financial services firms to deal with an expanding amount of regulation. Such expanding regulation imposes costs on financial firms. Yet, snowballing regulation also provides incentives for creating the new compliance innovations which have made companies like Thompson Reuters, Capco and others large and important players in the financial services sector.

The relationship between financial regulation and compliance-related legal advisors helps determine a jurisdiction's competitiveness. A growing compliance and legal sector can make financial firms more internationally competitive. Yet, such growth can also encourage regulators to increase costly regulation - even if financial services firms' compliance capacity does not yet exist. Tying regulator's objectives to financial firms' profitability can help reduce the extent of ever-increasing regulatory burdens. Engaging in regular deregulation exercises and encouraging the sharing of compliance best-practice can also help. In the end, the growth of financial firms' profits and regulation depends on the extent to which competition among financial firms leads to compliance-related innovation.

\section{References}

Abrams, David and Albert Yoon. (2007). The Luck of the Draw: Using Random Case Assignment to Investigate Attorney Ability. University of Chicago Law Review 74(4).

Acharya, Viral. (2009). A theory of systemic risk and design of prudential bank regulation. Journal of Financial Stability 5(3): 224-255. 
Aigbe Akhigbe and Anna Martin. (2006). Valuation impact of Sarbanes-Oxley: Evidence from disclosure and governance within the financial services industry. Journal of Banking \& Finance 30(3): 989-1006.

Allen \& Overy. (2012). Innovation In-House: A Five-Year Retrospective. Available at: http://rsgconsulting.com/wp-content/uploads/2013/10/Innovation-in-house-a-five-yearretrospective-AO-PDF.pdf.

Barth, James, Gerard Caprio, and Ross Levine. (2013). Bank Regulation and Supervision in 180 Countries from 1999 to 2011. Journal of Financial Economic Policy 5(2): 111-219.

Barth, James, Daniel Nolle, Triphon Phumiwasana and Glenn Yago. (2003).

A Cross-Country Analysis of the Bank Supervisory Framework and Bank Performance Financial Markets, Institutions \& Instruments 12(2): 67-120.

Beck, Thorsten. 2008. Bank Competition and Financial Stability: Friends or Foes? World Bank Policy Research Working Paper 4656.

Beltratti, Andrea and Rene Stulz. (2009). Why Did Some Banks Perform Better during the Credit Crisis? A Cross-Country Study of the Impact of Governance and Regulation. Finance Working Paper 254/2009.

Boot, Arnoud and Anjan Thakor. (2006). Self-Interested Bank Regulation. American Economic Review 83(2): 206-212.

Brunnermeier, Markus and Yuli Sannikov. (2014). A Macroeconomic Model with a Financial Sector. American Economic Review 104(2): 379-421.

Cihak, Martin, Asli Demirgüç-Kunt, Maria Soledad Martinez Peria, and Amin MohseniCheraghlou. (2013). Bank regulation and supervision in the context of the global crisis. Journal of Financial Stability 9(4): 733-746.

Cunningham, Lawrence and David Zaring, (2010). The Three or Four Approaches to Financial Regulation: A Cautionary Analysis against Exuberance in Crisis Response. George Washington Law Review 78(39).

De Serres, Alain, Shuji Kobayakawa, Torsten Sløk and Laura Vartia. (2006). Regulation of Financial Systems and Economic Growth in OECD Countries: An Empirical Analysis. OECD Economic Studies No. 43.

Dehnad, Kosrow and Darius Dehnad. (2013). Optimal Business Model for Financial Institutions under Post-Crisis Regulatory Environment. Capco Institute Journal of Financial Transformation. 
Dobson, Wendy and A. Kashyap. (2006). The Contradiction in China's Gradualist Banking Reforms. Brookings Papers on Economic Activity 2: 103-162.

Galanter, Marc and William Henderson. (2008). The Elastic Tournament: A Second Transformation of the Big Law Firm. Stanford Law Review 60(6).

Garicano, Luis and Thomas Hubbard. (2009). Specialization, Firms, and Markets: The Division of Labor within and between Law Firms. Journal of Law, Economics, and Organization 25(2): 339-371.

Garten, Helen. (1989). Regulatory Growing Pains: A Perspective on Bank Regulation in a Deregulatory Age. Fordham Law Review 57(4): 501-577.

Goodhart, C. (2005). Financial Regulation, Credit Risk and Financial Stability. National Institute Economic Review 192(1): 118-127.

Harper, Steven. (2013). The Lawyer Bubble: A Profession in Crisis. Basic Books.

Helleiner, Eric and Stefano Pagliari. (2011). The End of an Era in International Financial Regulation? A Postcrisis Research Agenda International Organization 65(1): 169-200.

Henderson, William. (2011). Three Generations of U.S. Lawyers: Generalists, Specialists, Project Managers. Maryland Law Review 70(373).

Iossa Elisabetta, and Bruno Jullien. (2009). The Market for Lawyers and the Quality of Legal Services.

Jackson, Howell. (2007). Variation in the Intensity of Financial Regulation: Preliminary Evidence and Potential Implications. Yale Journal on Regulation 24(253).

Jain, Pankaj and Zabihollah Rezaee. (2006). The Sarbanes-Oxley Act of 2002 and Capital-Market Behavior: Early Evidence. Contemporary Accounting Research 23(3): 629-654.

Krieger, Lawrence and Kennon Sheldon. (2015). What Makes Lawyers Happy? Transcending the Anecdotes with Data from 6200 Lawyers. George Washington University Law Review 83.

Krishnan, Jayanth. (2007). Outsourcing and the Globalizing Legal Profession. William and Mary Law Review 48(2189).

La Porta, Rafael, Florencio Lopez De Silanes and Andrei Shleifer. (2006). What Works in Securities Laws? The Journal of Finance 61(1): 1-32.

Langevoort, Donald. (2012). Getting (Too) Comfortable: In-House Lawyers, Enterprise Risk, and the Financial Crisis. Wisconsin Law Review 495. 
Le Leslé, F. Ohnsorge, M. Kim, and S. Seshadri. (2014). Why Complementarity Matters for Stability-Hong Kong SAR and Singapore as Asian Financial Centers. IMF Working Paper 14/119.

Morrison, Alan and Lucy White. (2009). Level Playing Fields in International Financial Regulation. Journal of Finance 64(3): 1099-1142.

Olson, Mary. (1999). Agency rulemaking, political influences, regulation, and industry compliance. Journal of Law, Economics, and Organization 15(3): 573-601.

Polinsky, Mitchell and Daniel Rubinfeld. (2003). Aligning the Interests of Lawyers and Clients. American Law and Economics Review 5(1): 165-188.

Quinn, Dennis. (1997). The Correlates of Change in International Financial Regulation. American Political Science Review 91(3): 531-551.

Quinn, Dennis and Carla Inclan. (1997). The Origins of Financial Openness: A Study of Current and Capital Account Liberalization. American Journal of Political Science 41(3): 771-813.

Rebitzer, James and Lowell Taylor. (1995). Efficiency Wages and Employment Rents: The Employer-Size Wage Effect in the Job Market for Lawyers. Journal of Labor Economics 13(4): 678-708.

Rosen, Robert. (2002). 'We're All Consultants Now': How Change in Client Organizational Strategies Influences Change in the Organization of Corporate Legal Services. Arizona Law Review 44 (637).

Rostain, Tanina. (2008). General Counsel in the Age of Compliance: Preliminary Findings and New Research Questions. Georgetown. Journal of Legal Ethics 21(465).

Mari Sako, George Chondrakis and Vaaler. (2013). How Do Firms Balance Making and Buying? The Case of Legal Services Sourcing by Fortune 500 Companies. Mimeo available at: https://test-intranet.law.ox.ac.uk/ckfinder/userfiles/files/Paper\%20\%20Sako\%20Chondrakis\%20Vaaler(1).pdf.

Schwarcz, Steven. (2008). To Make or to Buy: In-House Lawyering and Value Creation. Journal of Corporate Law 33(497).

Silver, Carole. (2003). Regulatory Mismatch in the International Market for Legal Services. Northwest Journal of International Law and Business 23(487).

Simmons, Omari and James Dinnage. (2011). Innkeepers: A Unifying Theory of the InHouse Counsel Role. Seton Hall Law Review 41(77).

Simon, William. (2012). Where is the "Quality Movement" in Law Practice? 
Wisconsin Law Review.

Tsolakis, James. (2014). A perspective on the legal market, RBS Working Paper, Available at:

http://www.rbs.com/content/dam/rbs/Documents/News/2014/03/perspective-on-the-legalmarket.pdf.

Vatnick, Silvina. (2008). Financial Reforms and Emerging Markets. Financial Markets, Institutions \& Instruments 17(1): 109-120.

Wallace, Jean and Marisa Young. (2008). Parenthood and Productivity: A Study of Demands, Resources and Family-Friendly Firms. Journal of Vocational Behaviour 72: 110-122.

Weinberg, John. (2002). Competition Among Bank Regulators. Federal Reserve Bank of Richmond Economic Quarterly 88(4): 19-36.

Wilcox, James. The Increasing Integration and Competition of Financial Institutions and of Financial Regulation. Research in Finance 22(1): 215-238. 


\section{Appendix I: A Numerical Measure of Regulation}

Relatively simple arithmetic operations can establish a scale on which to evaluate the similarity or difference between countries' banking (and securities) regulations. Such a measure would allow compliance services providers to estimate the amount of work and type of work clients in a new market. For example, do Thai banks need advice closer to Hong Kong's or to Singapore's? The numerical measure we provide in this appendix helps them answer this question. Such a measure might also go some way as measure for $\mathrm{R}$ (the stock of regulations) in our model.

Equation (I) shows one possible way of mapping the complex vector values for a country's financial regulation into a scalar number. Let $X_{i}$ equal the factor loading along one of four orthogonal dimensions we found using the Cihak et al. (2013) database for financial regulation. As described in this paper's main body text, the procedure compares a $j$-element column vector of values ranging from 0 to $\mathrm{m}$ for each country $i$ with other countries. Each country receives a score along each of these four orthogonal dimensions, depending on the extent to which the variance between various elements of $r$ correspond to each other. Such a mapping assigns weights to each of four factors or dimensions which range between minus 1 and 1 .

We can compute a relatively simple measure of financial regulations as follows. As shown in equation (I), we can simply add the absolute value of the factor loadings for each of the four dimensions. We use absolute values between negatives and positives emerge from the multidimensional scaling process only as a mathematical construct with negative elements assigned to dimension 1 and position to dimension 2. Equation (II) shows the procedure used to scale the resulting sums onto the unit line. Figures Ia, Ib and Ic show the actual results of such a mapping and scaling on each country's banking regulation. According to the mapping we used, a country receives a lower regulatory score $(R)$ the more similar the country's banking regulations are to Germany's. ${ }^{31}$ According to this scaling, Bulgaria's banking laws represent the furthest (most dissimilar) to the majority of other countries' laws.

$$
\mathbf{X}_{i}=\mathbf{X}_{\mathbf{i}}\left(r_{11}, r_{12}, \ldots, r_{1 n}\right)=\sum_{z=1}^{4}\left|\chi_{z}\right| \hat{z} \mid-1 \leq \chi_{z} \leq 1
$$

and if $\hat{z}=\{a, b, c, d\}$, then $\sum_{z=1}^{4} \chi_{z} \hat{z}=\chi_{1} \hat{a}+\chi_{2} \hat{b}+\chi_{3} \hat{c}+\chi_{4} \hat{d}$

$$
R=1-\frac{w+\min (w)}{\max (w)}|w=| \chi_{1}\left|-\sum_{z=2}^{4}\right| \chi_{Z} \mid
$$

Such a measure differs from Barth et al. (2013) index in that this measure does not try to subjectively decide whether specific values of $r_{i j}$ represent more or less stringent

\footnotetext{
${ }^{31}$ According to this method of scaling the data, Germany most represents the prototypical country. In our multidimensional scaling procedure, 87 out of 118 countries had the largest absolute value of $\chi_{1}$.
} 
regulatory requirements. This measure differs from "outcome based" measures like those used in Quinn and Inclan (1997) in that it measures regulations directly, rather than the effects of these regulations on capital ratios, concentration and other variables. ${ }^{32}$

\section{Figure Ia: Distance from Major Financial Centres’ Banking Regulation} (regulatorily "close" to major markets)

\begin{tabular}{|lclclc|}
\hline \multicolumn{1}{c}{ Country } & Score & \multicolumn{1}{c}{ Country } & Score & \multicolumn{1}{c}{ Country } & Score \\
\hline Germany & 1.00 & Kazakhstan & 0.68 & Venezuela & 0.57 \\
\hline USA & 0.97 & Ireland & 0.66 & Mexico & 0.57 \\
\hline China & 0.96 & Australia & 0.65 & Russia & 0.57 \\
\hline France & 0.96 & Gibraltar & 0.65 & Malaysia & 0.56 \\
\hline Austria & 0.94 & Lebanon & 0.65 & Virgin Islands & 0.56 \\
\hline Jersey & 0.92 & Bahrain & 0.63 & Hungary & 0.55 \\
\hline Luxembourg & 0.88 & Slovakia & 0.63 & Trinidad & 0.55 \\
\hline Denmark & 0.85 & Cyprus & 0.62 & Canada & 0.55 \\
\hline United Kingdom & 0.84 & Croatia & 0.61 & Latvia & 0.54 \\
\hline Ukraine & 0.83 & Lithuania & 0.59 & Netherlands & 0.53 \\
\hline Lichtenstein & 0.78 & Puerto Rico & 0.58 & Estonia & 0.52 \\
\hline Italy & 0.76 & Switzerland & 0.58 & Jordan & 0.50 \\
\hline Norway & 0.72 & Portugal & 0.58 & Egypt & 0.50 \\
\hline Finland & 0.71 & Colombia & 0.58 & Bangladesh & 0.50 \\
\hline
\end{tabular}

Figure Ib: Distance from Major Financial Centres’ Banking Regulation (regulatorily between the major and periphery markets)

\begin{tabular}{|lclc|lc|}
\hline Country & Score & \multicolumn{1}{c}{ Country } & Score & Country & Score \\
\hline New Zealand & 0.49 & Myanmar & 0.38 & Macao & 0.33 \\
\hline Belgium & 0.49 & Hong Kong & 0.38 & Guyana & 0.32 \\
\hline Cayman Islands & 0.48 & Korea & 0.38 & Morocco & 0.32 \\
\hline Thailand & 0.48 & Sri Lanka & 0.38 & Nepal & 0.31 \\
\hline Indonesia & 0.44 & Dominican Rep. & 0.37 & Slovenia & 0.31 \\
\hline Mauritius & 0.44 & Maldives & 0.37 & Yemen & 0.30 \\
\hline India & 0.43 & Surinam & 0.37 & Peru & 0.28 \\
\hline Isle of Man & 0.43 & Vanuatu & 0.37 & Brazil & 0.28 \\
\hline Spain & 0.41 & Bosna-HZ & 0.36 & Panama & 0.27 \\
\hline Tajikistan & 0.39 & Kosovo & 0.35 & Seychelles & 0.26 \\
\hline
\end{tabular}

\footnotetext{
${ }^{32}$ See Quinn (1997) for a further discussion of the way economists and political scientists measure the way financial regulations affect macroeconomic variables and even attributes of political structure by looking at the effects of such financial regulations on the levels of key banking and securities outcomes. In contrast, authors like Beltratti and Stulz (2009) look at the way that these proxies for regulations impact on macroeconomic variables.
} 


$\begin{array}{|llllll|}\text { Romania } & 0.39 & \text { Tunisia } & 0.34 & \text { Gambia } & 0.26 \\ \text { Burkina Faso } & 0.39 & \text { Fiji } & 0.34 & \text { Montenegro } & 0.26 \\ & & \text { Belize } & 0.34 & \text { Kyrgyz } & 0.25\end{array}$

Figure Ic: Distance from Major Financial Centres’ Banking Regulation

(regulatorily far the major markets)

\begin{tabular}{|l|rlrlr|}
\hline Country & Score & \multicolumn{1}{c}{ Country } & Score & \multicolumn{1}{c|}{ Country } & Score \\
\hline Bhutan & 0.25 & Poland & 0.19 & Uganda & 0.13 \\
\hline Philippines & 0.25 & Nicaragua & 0.19 & Paraguay & 0.12 \\
\hline Kenya & 0.24 & Samoa & 0.18 & Turkey & 0.12 \\
\hline Guernsey & 0.24 & Ecuador & 0.17 & Oman & 0.12 \\
\hline Qatar & 0.24 & Costa Rica & 0.17 & El Salvador & 0.12 \\
\hline Iceland & 0.24 & Chile & 0.17 & Uruguay & 0.12 \\
\hline Israel & 0.23 & UAE & 0.16 & Greece & 0.11 \\
\hline Honduras & 0.23 & Cook Islands & 0.16 & Argentina & 0.10 \\
\hline Syria & 0.23 & Kuwait & 0.15 & Belarus & 0.10 \\
\hline Jamaica & 0.23 & South Africa & 0.14 & Malta & 0.07 \\
\hline Armenia & 0.22 & Pakistan & 0.14 & Taiwan & 0.07 \\
\hline Moldova & 0.22 & Serbia & 0.14 & Bulgaria & 0.00 \\
\hline Madagascar & 0.22 & & & & \\
\hline Guatemala & 0.20 & & & & \\
\hline
\end{tabular}

